\title{
Nuevas edades U-Pb SHRIMP del Complejo Volcánico Agua de la Piedra, Provincia Magmática Somún Curá, Patagonia, Argentina
}

\author{
Flavia M. Salani ${ }^{1, *}$, Marcela B. Remesal ${ }^{1}$ y João O.S. Santos ${ }^{2}$ \\ ${ }^{1}$ Departamento de Ciencias Geológicas, FCEN, Universidad de Buenos Aires-IGEBA, CONICET, \\ Pabellón II, Ciudad Universitaria, Buenos Aires, 1425, Argentina. \\ ${ }^{2}$ Center of Exploration Targeting, University of Western Australia, \\ 35 Stirling Highway, Perth, WA, Australia. \\ *flaviamsalani@gmail.com
}

\section{RESUMEN}

Durante el Cenozoico, el Norte de la Patagonia Extraandina se caracterizó por un extenso magmatismo, principalmente Oligoceno (25-28Ma) y basáltico, el plateau de Somún Curá. Un estadio post meseta más joven está representado por distintos complejos volcánicos poligenéticos (Alta Sierra de Somún Curá, Sierra de Apas, Sierra de Telsen, Sierra de Talagapa, Sierra Pire Mahuida, y Sierra de Chacays) y centros monogenéticos menores (Trayén Niyeu, Cerro Dos Hermanos) desarrollados desde el Oligoceno tardío hasta el Mioceno. Hasta el presente el complejo Agua de la Piedra ha sido considerado un centro eruptivo post meseta. Este edificio volcánico está compuesto por flujos piroclásticos basales de composición traquítica, lavas y domos traquíticos y cantidades menores de riolita, culminando con flujos basálticos. La serie se caracteriza por su naturaleza alcalina y muestra una brecha composicional típica en el rango mesosilícico. La evolución inferida de las rocas básicas hasta los términos diferenciados traquita-riolita habría estado controlada mediante el fraccionamiento temprano de olivina-clinopiroxeno y posteriormente por plagioclasa + cristalización de K-feldespato. Hay escasos datos geocronológicos de esta serie volcánica. Para determinar con precisión la edad de la secuencia bimodal, se realizaron análisis U- $\mathrm{Pb}$ (SHRIMP) en muestras seleccionadas de un flujo de lava de traquita (Puesto Navarrete; $32.32+0.48$-0.98 Ma), que constituye el núcleo del Complejo, y de un flujo de riolita en el sector periférico (Puesto Suárez; $32.01+0.51-0.34 \mathrm{Ma}$ ). La facies basáltica fue fechada por la metodología K-Ar en $24.4 \pm 0.9 \mathrm{Ma}$. En conjunto, las nuevas edades reubican el Complejo Volcánico Agua de la Piedra en el contexto evolutivo de la Provincia Magmática Somún Curá. A la luz de la nueva información geocronológica que se presenta es evidente que las rocas traquíticas y riolíticas se habrían formado en forma sincrónica o poco antes que el evento principal que formó la meseta mientras que las edades de las rocas basálticas evidencian una contemporaneidad con otros complejos volcánicos post meseta.

Palabras clave: Patagonia Extraandina; Vulcanismo neógeno; Agua de la Piedra; Petrología-Geocronología.

\author{
ABSTRACT \\ During the Cenozoic, the northern extra-Andean Patagonia was \\ characterized by an extensive magmatism, mainly Oligocene (25-28Ma) \\ and basaltic, i.e. the Somún Curá plateau. Younger, post-plateau mag-
}

matism produces several polygenetic volcanic complexes (Alta Sierra de Somún Curá, Sierra de Apas, Sierra de Telsen, Sierra de Talagapa, Sierra Pire Mahuida, and Sierra de Chacays) and minor monogenetic centres (Trayén Niyeu Volcano, Dos Hermanos Hills), developed from Late Oligocene through Miocene times. Up to the present, the Agua de la Piedra Volcanic Complex has been considered a post-shield eruptive assemblage. This volcanic building is composed of basal pyroclastic flows of trachytic composition and lava flows and domes which span from trachyte and lesser amounts of rhyolite to late basaltic flows. The series is characterized by its alkaline composition and displays a typical compositional gap in the mesosilicic realm. The evolution from the basic rocks to the trachyte-rhyolite differentiates was controlled by early olivine-clinopyroxene fractionation and later by plagioclase $+K$ feldspar crystallization. There are scarse geocronological data of this volcanic series. In order to precisely date the bimodal sequence, a trachyte lava flow (Puesto Navarrete; $32.32+0.48-0.98 \mathrm{Ma}$ ), which constitutes the core of the Complex, and another rhyolite flow (Puesto Suárez; $32.01+0.51$ $-0.34 \mathrm{Ma}$ ) were selected to perform $\mathrm{U}-\mathrm{Pb}$ Sensitive High Resolution Ion MicroProbe (SHRIMP) analyses. The basaltic facies was dated by $\mathrm{K}-\mathrm{Ar}$ methodology at $24.4 \pm 0.9 \mathrm{Ma}$. All in all, the ages pose new time constraints in the Agua de la Piedra Volcanic Complex within the evolutive context of the Somún Curá Magmatic Province. The new geochronological information obtained indicate that the trachytic and rhyolitic rocks would have formed synchronously or shortly before the main event that formed the plateau, while the ages of the basaltic rocks are bound to be coeval with other post plateau volcanic complexes.

Key words: Extra- Andean Patagonia; Neogene volcanism; Agua de la Piedra; Petrology-Geocronology.

\section{INTRODUCCIÓN}

El Complejo Volcánico Agua de la Piedra (CVAP) está constituido por una asociación lávico piroclástica, emplazada en el norte de la Patagonia extrandina, entre los paralelos $41^{\circ} 35^{\prime}$ y $41^{\circ} 45^{\prime}$ y los meridianos $68^{\circ} 50^{\prime}$ y $69^{\circ}$ (Figura 1). Ha sido considerado (Remesal et al., 2001, 2002, 2006; Salani et al., 2006) como un exponente del magmatismo post meseta dentro de la Provincia Magmática de Somún Curá (de edad oligocena-miocena), integrada por una primer etapa efusiva que forma una extensa meseta basáltica y un conjunto de complejos bimodales traquítico basálticos tradicionalmente asignados a una segunda etapa efusiva. Esta etapa post meseta se emplaza como 
sierras en el interior y la periferia de la meseta basáltica (centros bimodales) y como centros monogenéticos menores de composiciones basálticas.

El vulcanismo basáltico inicial de la meseta de Somún Curá, las efusiones monogenéticas y los complejos bimodales, se han emplazado contemporáneamente al régimen tectónico extensional que caracteriza el Oligoceno tardío-Mioceno inferior en el arco andino, con desarrollo de cuencas de antearco o retroarco (Remesal et al. 2012). El margen Pacífico de Sudamérica estaba entonces dominado por un movimiento de tipo transcurrente (Somoza y Ghidella, 2005) que duró hasta hace $\sim 25 \mathrm{Ma}$. El magmatismo de Agua de la Piedra se encuentra en el área transicional entre el arco y el antepaís a $350 \mathrm{~km}$ de la trinchera donde continúa la dinámica extensional relacionada al arco andino (Figura 1).

La primer caracterización estratigráfica y litológica del vulcanismo de Agua de La Piedra fue realizada en el marco del levantamiento de las Hojas Geológicas Maquinchao 4169-IV (Remesal et al. 2001) y 4166IV Ingeniero Jacobacci (González et al. 2011). Remesal et al. (2002) presentaron un estudio más detallado de la estratigrafía incluyendo la cartografía y descripción de las facies litológicas predominantes. El objetivo de esta contribución es dar a conocer los resultados sobre la composición del Complejo Volcánico Agua de la Piedra (CVAP) y particularmente las nuevas evidencias sobre la edad de la sucesión que permiten precisar el evento temporal y replantear los modelos conocidos hasta el presente.

\section{EL COMPLEJO AGUA DE LA PIEDRA}

La secuencia responde a una estructura semicircular elongada en dirección NE-SO (Figura 2). Esta estructura está enmarcada por derrames mesetiformes de basaltos y en su núcleo predominan rocas diferenciadas en facies lávicas y piroclásticas interdigitadas, vinculadas a aparatos volcánicos menores. Los basaltos mesetiformes que rodean la sierra por el oeste están separados de los centros de emisión del
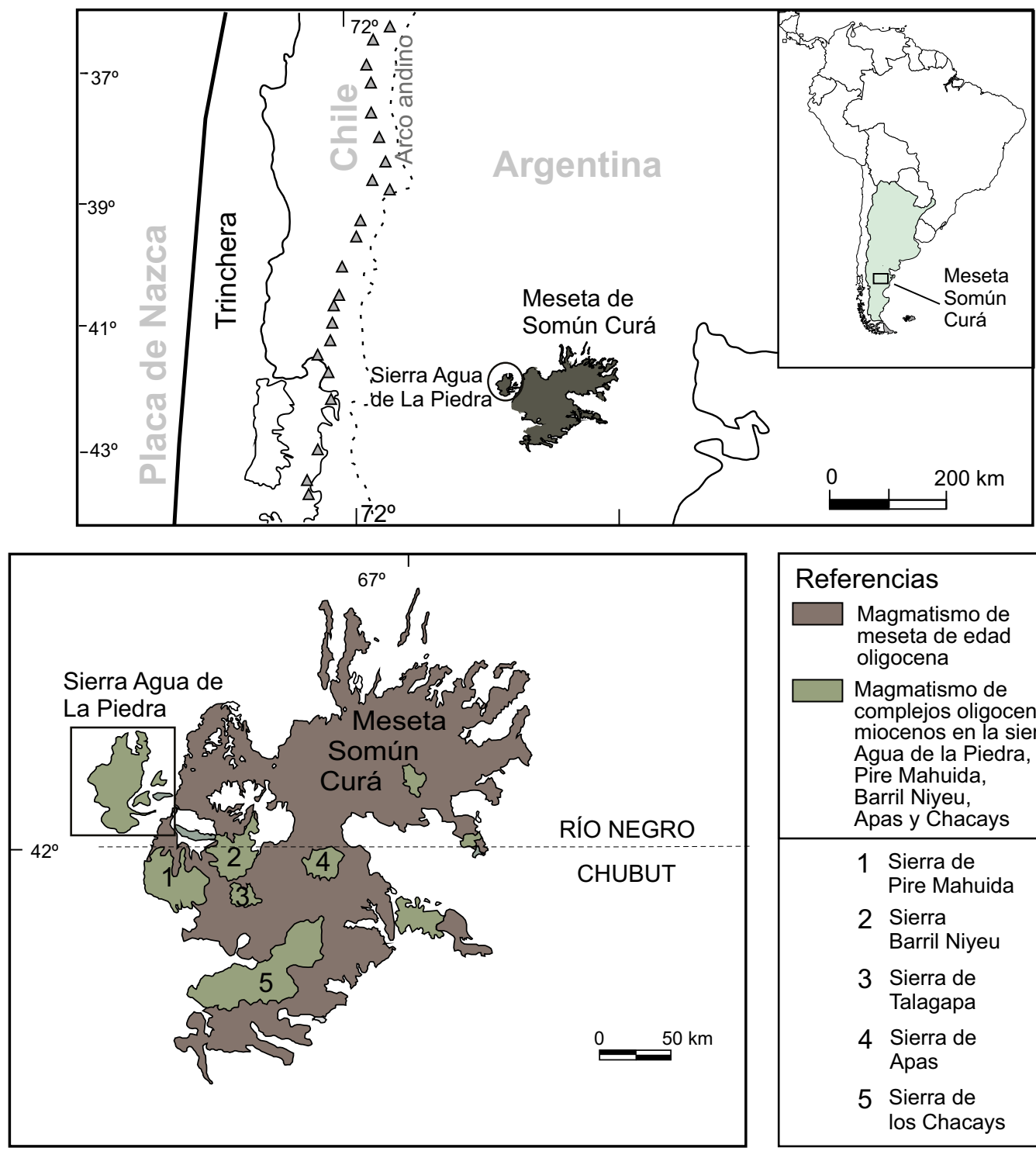

\begin{tabular}{|l|l|}
\hline \multicolumn{1}{|c|}{ Referencias } \\
\hline \\
Magmatismo de \\
meseta de edad \\
oligocena \\
Magmatismo de \\
complejos oligoceno- \\
miocenos en la sierra \\
Agua de la Piedra, \\
Pire Mahuida, \\
Barril Niyeu, \\
Apas y Chacays \\
\hline 1 Sierra de \\
$\quad$ Pire Mahuida \\
2 Sierra \\
Barril Niyeu \\
3 Sierra de \\
Talagapa \\
4 Sierra de \\
Apas \\
5 Sierra de \\
los Chacays
\end{tabular}

Figura 1. Mapa de ubicación de la Sierra Agua de la Piedra en el contexto de la Provincia Magmática Somún Curá con los principales elementos tectónicos del norte de la Patagonia. Se destaca la localización periférica de los Complejos Volcánicos Agua de la Piedra, Pire Mahuida, Chacays y Telsen y la disposición en sectores centrales de los complejos Apas, Barril Niyeu y Alta Sierra de Somún Curá. 
núcleo del complejo por una depresión marcada por asentamientos que reflejan la erosión del contorno original.

De acuerdo con la composición y relaciones estratigráficas el CVAP fue enmarcado dentro de la Superunidad Quiñelaf por (Franchi et al., 2001). Esta unidad fue propuesta para incluir los diferentes complejos volcánicos (Alta Sierra de Somún Curá, Apas, Talagapa, etc.) considerados de emplazamiento post meseta en el ambiente de los derrames basálticos oligocenos de Somún Curá. El CVAP constituye la más occi- dental de las asociaciones de la Superunidad Quiñelaf, concentrándose en una serranía que le da nombre al Complejo, con alturas de hasta 1400 msnm constituida por rocas de composición esencialmente traquítica (Remesal et al., 2002), limitada por mesetas basálticas (Figura 2). El conjunto descansa sobre los depósitos cretácicos de las Formaciones Angostura Colorada y Coli Toro y sobre las rocas volcaniclásticas oligocenas del Grupo Sarmiento (Remesal et al., 2001) lo cual permite asignarle al CVAP una edad oligocena o más joven.

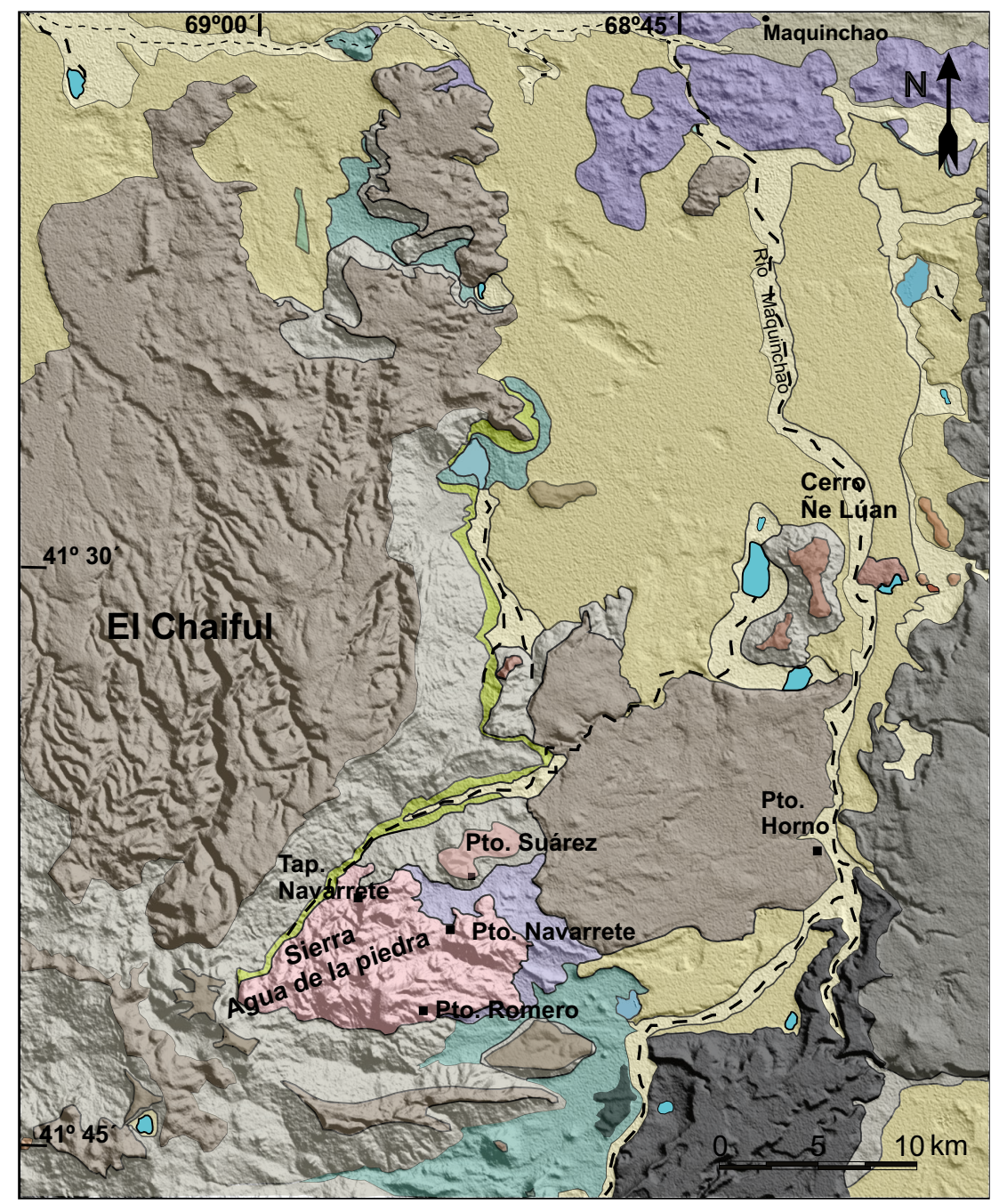

\begin{tabular}{|c|c|c|c|c|c|}
\hline \multicolumn{6}{|c|}{$\begin{array}{ll}\text { Referencias } \\
\end{array}$} \\
\hline$a^{Q^{b}}$ & \multicolumn{3}{|c|}{$\begin{array}{l}\text { Depósitos a) de deslizamiento, } \\
\text { b) de bajada y aluviales }\end{array}$} & Eoc. & $\begin{array}{l}\text { Formación Cerro Cortado, } \\
\text { Intrusivos basálticos }\end{array}$ \\
\hline Mio & \multicolumn{2}{|c|}{ Complejo Volcánico Pire } & \multirow{3}{*}{$\frac{\pi}{2}$} & & \\
\hline \multirow{5}{*}{ Mio } & \multirow{2}{*}{\multicolumn{2}{|c|}{$\begin{array}{l}\text { Complejo Volcánico } \\
\text { Barril Niyeu. Basaltos }\end{array}$}} & & $\mathbf{K}$ & Formación Coli Toro, \\
\hline & & & & & \\
\hline & Lavas Basálticas & \multirow{3}{*}{$\begin{array}{l}\text { Complejo } \\
\text { Volcánico } \\
\text { Agua de la } \\
\text { Piedra }\end{array}$} & $\frac{\pi}{\pi}$ & K & $\begin{array}{l}\text { Formaclon Angostura } \\
\text { Colorada, rocas sedimentarias }\end{array}$ \\
\hline & $\begin{array}{l}\text { Lavas y domos de } \\
\text { traquita y riolita }\end{array}$ & & 音 & $\operatorname{Tr}$ & $\begin{array}{l}\text { Complejo Los Menucos } \\
\text { Lavas y piroclastitas }\end{array}$ \\
\hline & $\begin{array}{l}\text { Piroclastitas } \\
\text { traquíticas }\end{array}$ & & & & unas,$\ldots$ ríos intermitentes \\
\hline
\end{tabular}

Figura 2. Mapa geológico del Complejo volcánico Agua de la Piedra, modificado de Remesal et al., (2002) con superposición de sombras calculadas de un modelo digital de elevación. 

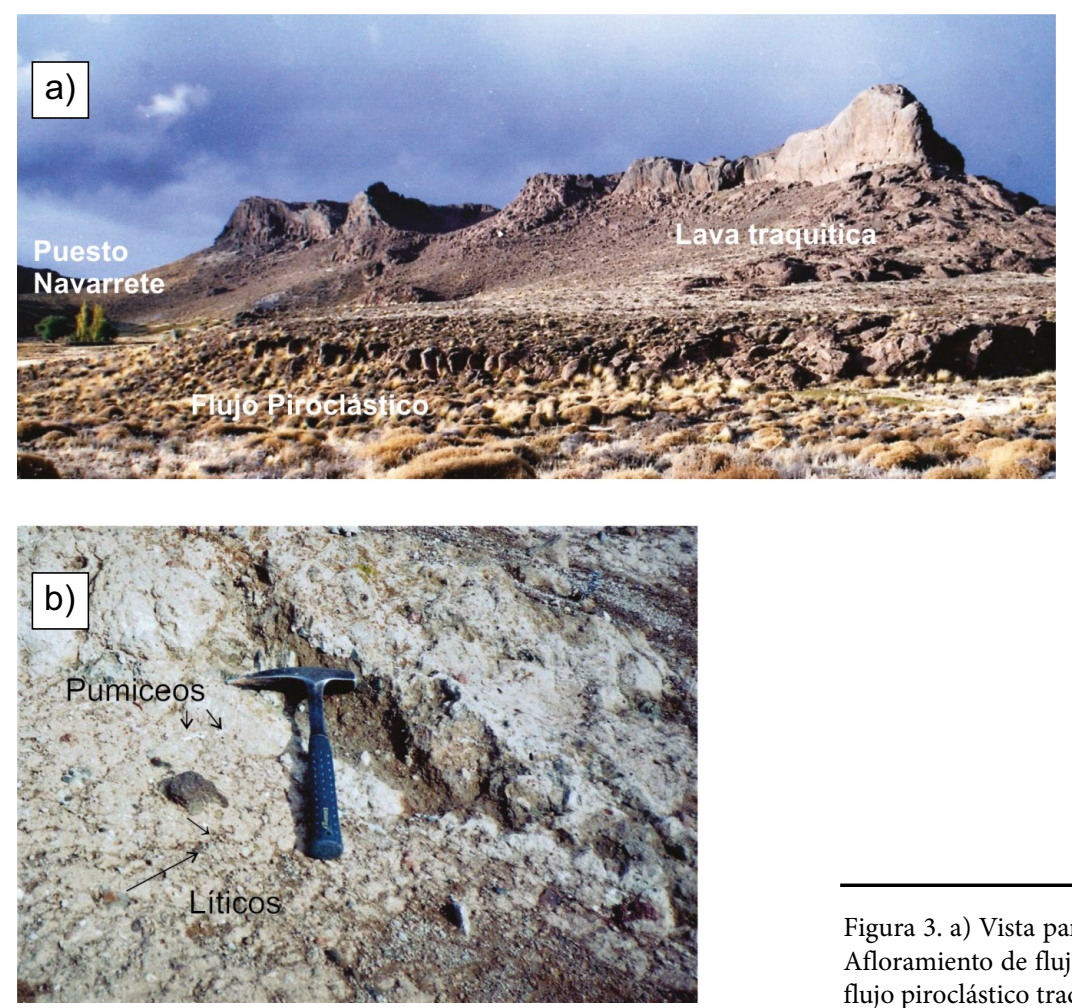

Figura 3. a) Vista panorámica de la Sierra Agua de la Piedra desde Puesto Navarrete. Afloramiento de flujo piroclástico en la base de la secuencia traquítica b) Detalle del flujo piroclástico traquítico.

El análisis volcano-estratigráfico indica que la secuencia de los eventos efusivos habría comenzado con la emisión de flujos piroclásticos, a posteriori de los cuales predominaron los flujos lávicos y dómicos de riolitas y traquitas. Finalmente, las efusiones basálticas culminan la secuencia.

De acuerdo a las características composicionales y rasgos texturales se dividió el CVAP en tres facies principales (Figura 2): a) piroclástica traquítica; b) lavas y domos de traquita y riolita y c) lávica basáltica.

\section{FACIES PIROCLÁSTICA TRAQUÍTICA}

Los depósitos piroclásticos, fundamentalmente flujos, muestran buenas exposiciones en el centro de la sierra (Figura 3a), en Puesto Navarrete y en el área norte, en la Tapera Navarrete (Figura 2). En Puesto Navarrete, cubierta por una potente secuencia traquítica $(200 \mathrm{~m})$, esta facies está representada por un depósito matriz soporte (Figura 3b), de color pardo, deleznable, sin estructura interna y conteniendo líticos de traquitas y hialotraquitas de hasta $4 \mathrm{~cm}$. Este nivel piroclástico -de un espesor promedio de 2 metros- puede seguirse con relativa continuidad hasta $5 \mathrm{~km}$ al oeste de puesto Horno, donde asoman cubiertos por coladas basálticas (Figura 2).

En la Tapera Navarrete aflora una secuencia, de 20 metros, que presenta en la base una brecha constituida por fragmentos angulosos de vulcanita de 0.4 a $2.5 \mathrm{~cm}$ (Figura 4.1), sucedida por depósitos de flujo piroclástico de color blanco, integrados mayormente por pumíceos en los niveles más bajos.

Los depósitos de flujo piroclástico se caracterizan por un incremento de la proporción de litoclastos (30\%) de vulcanitas (traquitas) hacia la parte superior de la unidad. El tamaño máximo de los litoclastos es $2 \mathrm{~cm}$. Sobre el flujo piroclástico se dispone una toba fina, con lentes de toba de grano grueso, en parte con laminación entrecruzada. Petrográficamente estos depósitos en general corresponden a tobas cristalolíticas, con cristales de plagioclasa, arfvedsonita y aegirina y fragmentos líticos de traquitas y piroclastitas (Figura 4.2). La matriz vítrea está compuesta por trizas en forma de burbuja y cristales fragmentados. Presenta un alto grado de alteración arcillosa y está cubierta por una pátina de óxidos de hierro. Se distinguen bancos silicificados, y un conglomerado (3 metros), con $70 \%$ de componentes líticos volcánicos que en algunos casos alcanzan $7 \mathrm{~cm}$ de longitud.

\section{FACIES DE LAVAS Y DOMOS DE TRAQUITA Y RIOLITA}

Las rocas lávicas diferenciadas forman el núcleo del Complejo, cubren un área aproximada de $200 \mathrm{~km}^{2}$ y determinan los relieves más prominentes. Los flujos tienen en promedio recorridos del orden de los 2 a $3 \mathrm{~km}$. Se han observado excelentes afloramientos en los alrededores de los Puestos Navarrete, Romero y Suárez.

\section{Traquitas}

\section{Flujos lávicos traquíticos}

En la Tapera Navarrete, cubriendo a los flujos piroclásticos, se presenta una secuencia constituida por dos variedades de traquita porfírica, una rica en cristales, de color rojo y otra brechosa con oquedades.

En el Puesto Navarrete, en el centro de la sierra (Figura 3a), aflora una potente secuencia de 30 metros compuesta por tres unidades de flujo traquítico, que se disponen sobre los depósitos de flujo piroclástico. Las dos primeras son de grano fino; la inferior bandeada, de color verde y gris por alteración y la superior masiva, rosado clara y fuertemente porfírica (30\% de fenocristales).

En el Puesto Romero, esta facies está representada por la variedad rica en cristales de color rosado. Aquí, el rasgo distintivo es un grado de alteración mayor y se destacan grandes oquedades y escapes de gases alineados que remarcan el bandeamiento por flujo. 

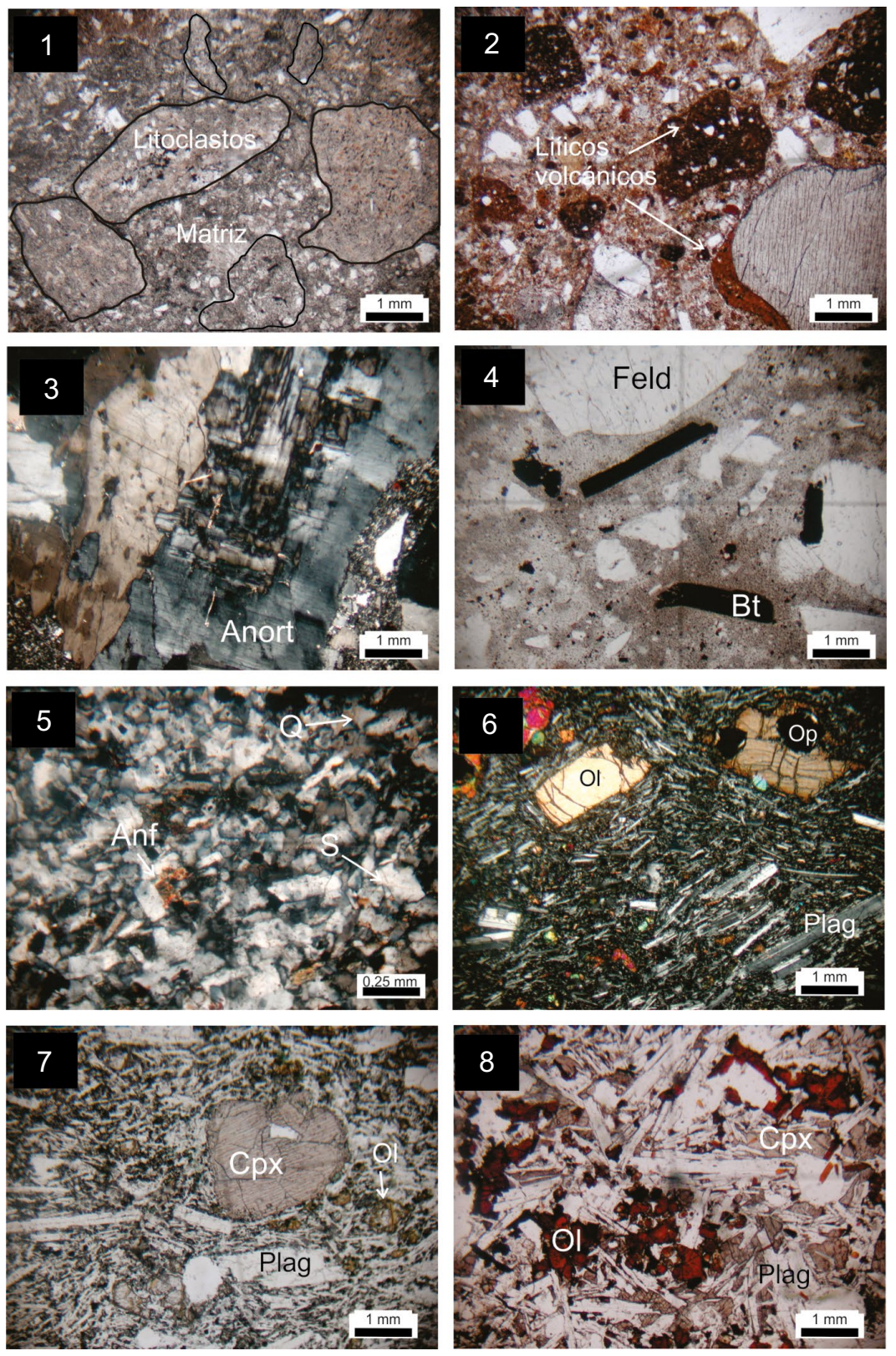

Figura 4. Mosaico de fotomicrografías de algunas muestras de las unidades volcánicas estudiadas por microscopia óptica. 1: Toba cristalolítica, en la cual se distinguen líticos volcánicos subredondeados, en el sector inferior derecho cristaloclasto de clinopiroxeno, cristales de feldespato alcalino y matriz parcialmente desvitrificada. 2: Brecha en la Tapera Navarrete con fragmentos angulosos y subangulosos, de vulcanitas cubiertos por pátina arcillosa. 3: Glomérulo de anortoclasa (Anort), con macla de Periclino y núcleo inhomogéneo. 4: Traquita porfírica con fenocristales de feldespato alcalino (Feld) y biotita (Bt) reemplazada por opacos. Pasta vítrea con fragmentos de cristales de diversos tamaños. 5: Lava dómica de composición traquitíca en Puesto Suárez. Pasta bostonítica compuesta por feldespatos alcalinos, sanidina (S) euhedral a subhedral, cuarzo (Q) intersticial y anfíbol alcalino (Anf) en cristales muy pequeños. 6: Microfenocristales de olivina (Ol), y minerales opacos en pasta pilotáxica, con mesostasis parcialmente desvitrificada. 7: Fenocristal de augita titanífera (Cpx), con bordes en desequilibrio con el líquido en una pasta fluidal de grano fino. 8: Basalto afírico, vesicular con pasta de textura intersertal gruesa integrada por plagioclasa, parches de augita titanífera (Cpx), olivina iddingsitizada $(\mathrm{Ol})$ y minerales opacos. El bandeamiento está definido por sectores con distinta participación de vidrio pardo.

Petrográficamente estas rocas en general son porfíricas a microporfíricas con fenocristales de feldespato alcalino (anortoclasa con exsoluciones y maclado) que a veces forman glomérulos de hasta $1 \mathrm{~cm}$ (Figura 4.3). Los cristales son subhedrales a anhedrales, con caras corroídas, maclado fino y extinción en parches. Ocasionalmente presentan rebordes más alcalinos.

De menor tamaño se presentan fenocristales de minerales máficos, biotita rica en $\mathrm{Ti}$, de coloración rojiza, con distintos estadios de alteración en opacos (Figura 4.4) e inclusiones de apatita coloreada. Menos comúnmente aparecen fantasmas de piroxenos totalmente reemplazados por arcillas. La pasta está integrada por sanidina, conformando una textura fluidal con microlitos de tamaños más o menos uniformes, en la que se destacan algunos de mayor desarrollo de anortoclasa, con bordes aserrados. Otras veces las tablillas están dispuestas al azar. Acompañan esta mineralogía hojuelas de mica y abundantes gránulos de opacos. 
Algunas variedades afíricas presentan anfíboles alcalinos de color verde azulado arfvedsonítico en agregados semiesferulíticos y un piroxeno verde, aegirínico. Intersticialmente pueden presentar material de desvitrificación arcilloso y tridimita.

El bandeamiento textural que presentan algunas rocas está definido por variación en el tamaño de los cristales, favorecido por la presencia diferencial de volátiles.

\section{Domos traquítícos}

En el Puesto Suárez, las traquitas forman un cuerpo dómico pequeño, con una potencia de aproximadamente $100 \mathrm{~m}$, con evidencias de flujo (Figura 5). La parte central del domo tiene estructuras cavernosas y está formada por una roca de textura granosa y con alteración, que resulta en el desarrollo de sectores porosos con rellenos de material arcilloso. Hacia los márgenes se incrementa la fluidalidad y aparece una roca bandeada. Petrográficamente la parte central corresponde a una traquita escasamente porfírica con fenocristales máficos en una pasta bostonítica, constituida esencialmente por sanidina y anortoclasa, con aegirina-augita subhedral y hojuelas de anfíbol arfvedsonítico, pleocroico del verde a pardo verde (Figura 4.5). La variedad más fluidal tiene texturas traquíticas con formación de cuarzo intersticial, parches de tridimita, y presenta los fenocristales reemplazados por opacos. El bandeamiento está definido por sectores con distinta participación de vidrio pardo en forma de lentículas oscuras. Por la composición, contornos y plasticidad, que muestran las lentículas se interpreta que corresponderían a fragmentos pumíceos colapsados y fundidos, en los que las evidencias de la estructura interna original habrían desaparecido.

\section{Riolitas}

Las riolitas están subordinadas en volumen a las traquitas. Un afloramiento aislado aparece al noroeste del Puesto Suárez y otro parcialmente brechoso está emplazado al sudeste del Puesto Romero, en el sector sur de la sierra. El primero es un cuerpo muy fluidal que muestra flexuramiento de flujo y estructuras en panal de abeja

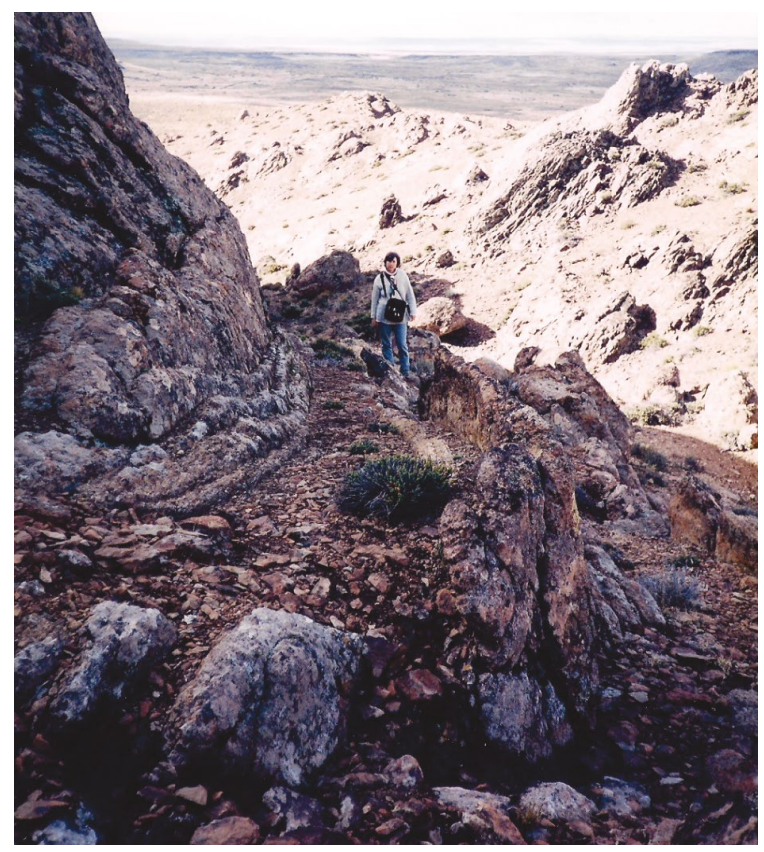

Figura 5. Domo traquítico en Puesto Suárez, mostrando la estructura interna $\mathrm{y}$ evidencias de flujo.

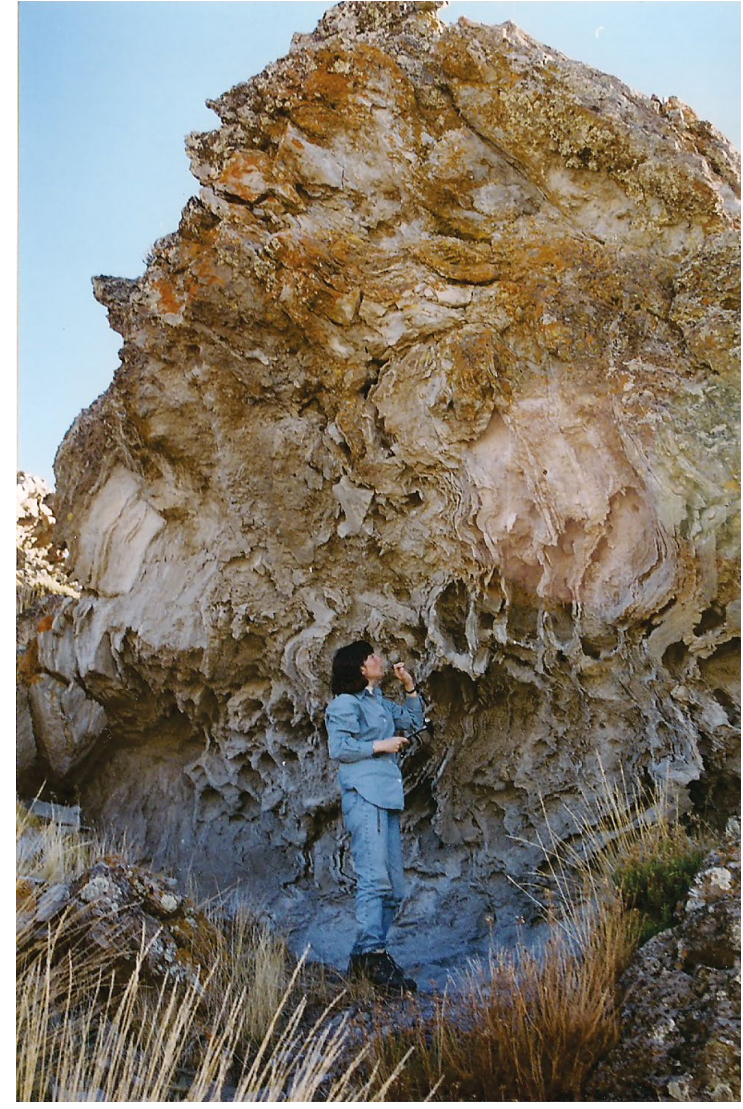

Figura 6. Lava riolítica al sur de El Chaiful ( $\left.41^{\circ} 40^{\prime} 4^{\prime \prime} \mathrm{S} 68^{\circ} 58^{\prime} 16^{\prime \prime O}\right)$ con evidencias de fluidalidad.

por escape de gases. Los filetes de flujo están lavados y resultan en oquedades y alineación de cavidades (Figura 6). En parte se distingue una autobrecha muy erosionada. La roca es una riolita porfírica con grandes fenocristales de cuarzo con bordes engolfados y en menor cantidad de feldespato alcalino. El feldespato es sanidina, límpida, en individuos subhedrales y euhedrales, equidimensionales al igual que en la pasta, por lo cual se los diferencia de los de anortoclasa. Se asocian formando glomérulos. Aparece mica castaña oscura, rica en $\mathrm{Ti}$, con los bordes reabsorbidos en opacos, reacción que en algunos cristales aparece generalizada. La pasta está compuesta por intercrecimientos microgranosos a felsíticos producto de desvitrificación y anfíbol verde azulado, pleocroico del pardo al verde oscuro, distribuido en toda la roca y orientado según la fluidalidad.

El flujo lávico del sector sur del Complejo (Puesto Romero, Figura 2) presenta una unidad brechosa inferior con clastos de riolita vítrea muy fina de $3-4 \mathrm{~cm}$ hasta bloques de $50 \mathrm{~cm}$, rodeada de lava vítrea que rompe en lajas finas. Aparecen tres niveles con disyunción columnar perfecta, más o menos apretada. Esta variedad es escasamente porfírica a glomeruloporfírica con pastas granofíricas y esferulíticas en la que se observan cristales mayores aislados, mosaicos de cuarzo poligonal, anfíbol alcalino anhedral y agujas de opacos.

\section{FACIES LÁVICA BASÁLTICA}

Las rocas basálticas afloran en forma discontinua en el sector sur mientras que hacia el norte constituyen extensos derrames mesetiformes. En esta facies se reconocen dos grandes grupos: 


\section{Basaltos porfíricos}

De afinidades claramente alcalinas. Afloran al sur del cerro Ne Luán y al oeste del Puesto Horno (Figura 2), donde se distinguen cuatro coladas de 1.5 a 2 metros de potencia, que apoyan sobre un flujo piroclástico correlacionable con el del puesto Navarrete. Son basaltos vesiculares y amigdaloides, de textura porfírica y glomeruloporfírica con fenocristales de plagioclasa (algunos engolfados), olivina iddingsitizada, augita titanífera de color rosado, maclada y cribada, con inclusiones de opacos (Figura 4.6 y 4.7). La pasta es intersertal, con olivina de tamaños intermedios, microlitos de clinopiroxeno, plagioclasa y minerales opacos. Las amígdalas presentan cristalización de ceolitas y arcillas.

\section{Basaltos afíricos}

Son basaltos olivínicos. Se extienden desde el sector oriental de la sierra hacia el norte y noroeste. Alcanzan distancias de varias decenas de kilómetros y pierden potencia en su recorrido. Cubren a las formaciones Angostura Colorada (Volkheimer,1973) y Coli Toro (Bertels , 1969) y/o al Grupo Sarmiento (Simpson, 1941).
En las estribaciones septentrionales se presentan con un espesor de aproximadamente 3 metros. Se distinguen tres unidades, con disyunción columnar marcada, trenes de vesículas en el interior y techos porosos y oxidados. Son rocas de tamaño de grano mediano a grueso y con texturas afíricas subofíticas. El conjunto mineralógico está integrado por olivina iddingsitizada, plagioclasa, augita titanífera, cristales aciculares de ilmenita y abundante carbonato formando amígdalas (Figura 4.8).

\section{GEOQUÍMICA}

Se presentan 7 análisis químicos de roca total (elementos mayores, menores y traza, Tabla 1) determinados por los métodos ICP-ES e INAA, según el procedimiento de determinaciones LITORESEARCH en Actlabs, Canadá.

De acuerdo a los resultados analíticos, las rocas del CVAP integran una serie alcalina bimodal con términos basálticos/traquibasálticos y traquíticos/riolíticos (Figura 7; Le Maitre et al., 1989).

Tabla 1. Determinaciones de elementos mayores en \% por peso, determinaciones de elementos menores y traza en ppm.

\begin{tabular}{|c|c|c|c|c|c|c|c|}
\hline & $\begin{array}{c}\text { MQ569 } \\
41^{\circ} 37^{\prime} 43^{\prime \prime} \\
68^{\circ} 49^{\prime} 2^{\prime \prime}\end{array}$ & $\begin{array}{c}\text { MQ596 } \\
41^{\circ} 33^{\prime} 47^{\prime \prime} \\
68^{\circ} 50^{\prime} 36^{\prime \prime}\end{array}$ & $\begin{array}{c}\text { MQ592ba } \\
41^{\circ} 41^{\prime} 22^{\prime \prime} \\
68^{\circ} 51^{\prime} 57^{\prime \prime}\end{array}$ & $\begin{array}{c}\text { MQ575 } \\
41^{\circ} 40^{\prime} 36^{\prime \prime} \\
68^{\circ} 55^{\prime} 19^{\prime \prime}\end{array}$ & $\begin{array}{c}\text { MQ599 } \\
41^{\circ} 40^{\prime} 4^{\prime \prime} \\
68^{\circ} 58^{\prime} 16^{\prime \prime}\end{array}$ & $\begin{array}{c}\text { MQ573 } \\
41^{\circ} 40^{\prime} 31^{\prime \prime} \\
68^{\circ} 55^{\prime} 26^{\prime \prime}\end{array}$ & $\begin{array}{c}\text { MQ570 } \\
41^{\circ} 38^{\prime} 01^{\prime \prime} \\
68^{\circ} 52^{\prime} 26^{\prime \prime}\end{array}$ \\
\hline $\mathrm{SiO}_{2}$ & 48.07 & 47.21 & 47.53 & 66.27 & 68.07 & 73.55 & 75.45 \\
\hline $\mathrm{Al}_{2} \mathrm{O}_{3}$ & 17.27 & 14.82 & 15.05 & 16.66 & 15.23 & 12.16 & 11.83 \\
\hline $\mathrm{Fe}_{2} \mathrm{O}_{3}(\mathrm{~T})$ & 12.02 & 11.46 & 12.52 & 3.26 & 3.47 & 2.99 & 2.57 \\
\hline $\mathrm{MnO}$ & 0.17 & 0.152 & 0.189 & 0.024 & 0.054 & 0.056 & 0.039 \\
\hline $\mathrm{MgO}$ & 5.62 & 8.07 & 6.74 & 0.17 & 0.33 & 0.06 & 0.04 \\
\hline $\mathrm{CaO}$ & 8.72 & 8.19 & 8.57 & 1.30 & 1.15 & 0.21 & 0.28 \\
\hline $\mathrm{Na}_{2} \mathrm{O}$ & 3.58 & 3.58 & 3.44 & 5.09 & 4.82 & 5.38 & 4.97 \\
\hline $\mathrm{K}_{2} \mathrm{O}$ & 1.29 & 1.04 & 1.64 & 5.62 & 5.15 & 4.32 & 4.20 \\
\hline $\mathrm{TiO}_{2}$ & 2.171 & 2.254 & 2.23 & 0.483 & 0.432 & 0.155 & 0.090 \\
\hline $\mathrm{P}_{2} \mathrm{O}_{5}$ & 0.63 & 0.62 & 0.71 & 0.14 & 0.18 & 0.03 & 0.05 \\
\hline LOI & 1.50 & 1.76 & 1.2 & 0.69 & 1.09 & 0.58 & 0.66 \\
\hline TOTAL & 99.05 & 99.16 & 99.83 & 99.72 & 99.97 & 99.49 & 100.18 \\
\hline $\mathrm{Rb}$ & 24.63 & 27 & 30 & 160 & 172 & 440 & 798 \\
\hline $\mathrm{Sr}$ & 687.62 & 784 & 752 & 186 & 169 & 17 & 14 \\
\hline $\mathrm{Y}$ & 23.2 & 21.7 & 24.8 & 32.3 & 36.2 & 56.0 & 137 \\
\hline $\mathrm{Zr}$ & 139.58 & 192 & 185 & 550 & 509 & 1.060 & 1.430 \\
\hline $\mathrm{Nb}$ & 31.94 & 52.6 & 43.2 & 73.9 & 85.4 & 271 & 518 \\
\hline $\mathrm{Ba}$ & 2270.00 & 699 & 587 & 734 & 545 & 30 & 11 \\
\hline $\mathrm{La}$ & 28.17 & 39.4 & 36.7 & 78.1 & 105 & 80.8 & 58.5 \\
\hline $\mathrm{Ce}$ & 63.81 & 76.0 & 67.4 & 172 & 187 & 154 & 131 \\
\hline $\operatorname{Pr}$ & 6.324 & 8.37 & 8.21 & 15.2 & 18.6 & 15.9 & 15.6 \\
\hline $\mathrm{Nd}$ & 26.35 & 34.5 & 31.1 & 52.6 & 64.8 & 53.5 & 60.3 \\
\hline Sm & 5.56 & 6.90 & 6.76 & 9.14 & 10.7 & 11.7 & 19.3 \\
\hline $\mathrm{Eu}$ & 2.009 & 2.33 & 2.17 & 1.42 & 1.47 & 0.211 & 0.119 \\
\hline $\mathrm{Gd}$ & 5.50 & 6.27 & 6.16 & 7.06 & 8.35 & 10.4 & 20.2 \\
\hline $\mathrm{Tb}$ & 0.79 & 0.90 & 0.9 & 1.11 & 1.28 & 1.98 & 4.30 \\
\hline Dy & 4.0 & 4.61 & 4.49 & 5.95 & 7.12 & 11.6 & 24.8 \\
\hline Ho & 0.72 & 0.83 & 0.8 & 1.08 & 1.41 & 2.31 & 4.90 \\
\hline Er & 1.87 & 2.11 & 2.13 & 3.18 & 4.05 & 6.95 & 14.5 \\
\hline $\operatorname{Tm}$ & 0.246 & 0.287 & 0.286 & 0.477 & 0.622 & 1.14 & 2.19 \\
\hline $\mathrm{Yb}$ & 1.43 & 1.65 & 1.76 & 2.90 & 4.00 & 7.76 & 13.2 \\
\hline $\mathrm{Lu}$ & 0.190 & 0.206 & 0.25 & 0.405 & 0.588 & 1.18 & 1.76 \\
\hline $\mathrm{Hf}$ & 3.16 & 4.8 & 4.2 & 11.9 & 13.1 & 32.7 & 48.7 \\
\hline $\mathrm{Ta}$ & 2.12 & 3.34 & 2.91 & 5.88 & 6.63 & 21.8 & 42.5 \\
\hline $\mathrm{Pb}$ & 2.632 & 6 & $<5$ & 11 & 19 & 11 & 94 \\
\hline Th & 0.707 & 4.59 & 3.51 & 21.1 & 25.5 & 52.2 & 91.9 \\
\hline $\mathrm{U}$ & 24.63 & 1.07 & 0.93 & 4.88 & 5.98 & 10.4 & 23.2 \\
\hline
\end{tabular}




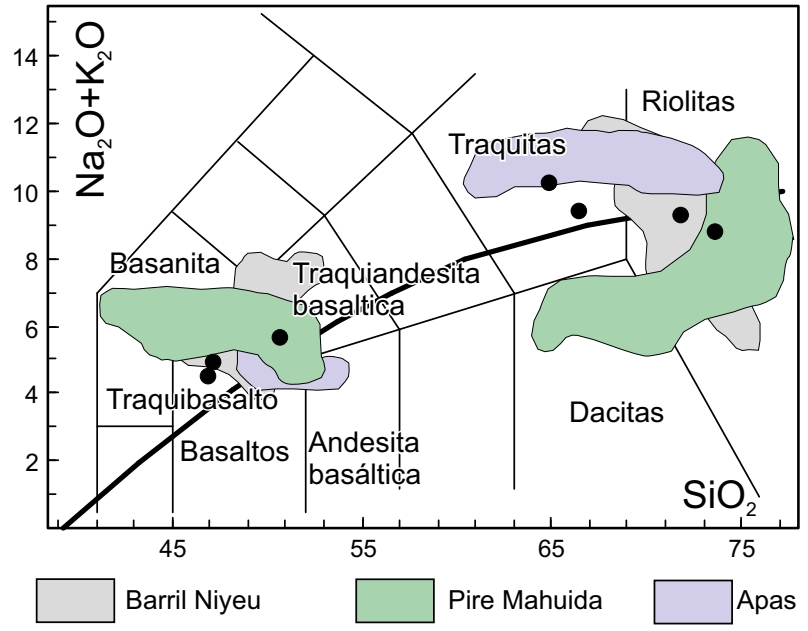

Figura 7. Clasificación de las rocas del Complejo Volcánico Agua de la Piedra según los parámetros de Le Maitre et al. (1989). A modo de comparación se dibujaron los campos representativos de muestras correspondientes al Complejo Volcánico Apas, al Complejo Volcánico Barril Niyeu (Remesal et al., 2006; 2012) y al Complejo Volcánico Pire Mahuida (Salani, 1990, 1996).

Los contenidos de sílice de los basaltos están entre $48-51 \%$ y las rocas más diferenciadas alcanzan un valor promedio de $75 \%$, así la información preliminar advierte sobre una brecha marcada entre 53 y $67 \%$ de $\mathrm{SiO}_{2}$. Brechas composicionales semejantes también fueron reconocidas en los otros complejos del ambiente post-meseta (Remesal et al., 2004 y Salani et al., 2006).

En términos comparativos, otros complejos como Apas y Barril Niyeu (Figura 1) tienen una distribución álcalis-sílice parecida (Figura 7). El carácter alcalino del CVAP se expresa en los elevados tenores de álcalis acompañados por la presencia de $\mathrm{Ol}$ y $\mathrm{Ne}$ en la norma de los basaltos y la ausencia de An en los términos traquítico-riolíticos.

$\mathrm{El} \mathrm{MgO}$ tiene una fuerte correlación negativa con la $\mathrm{SiO}_{2}$, evidenciando el fraccionamiento de olivina especialmente en el rango de los basaltos y alcanza valores muy bajos en las rocas diferenciadas (Figura 8a).
La relación $\mathrm{CaO} / \mathrm{Al}_{2} \mathrm{O}_{3}$ puede ser utilizada como índice de fraccionamiento de clinopiroxeno. $\mathrm{El} \mathrm{CaO}$ muestra rangos de valores amplios mientras el $\mathrm{Al}_{2} \mathrm{O}_{3}$ se mantiene esencialmente constante para el grupo de basaltos sugiriendo una línea de descenso del líquido con fraccionamiento de olivina y clinopiroxeno. $\mathrm{El} \mathrm{CaO}$ se correlaciona positivamente con la relación $\mathrm{CaO} / \mathrm{Al}_{2} \mathrm{O}_{3}$, y esta tendencia muestra que es improbable el fraccionamiento de plagioclasa en los términos básicos, lo cual es coincidente con la fuerte variación de pendiente de la relación $\mathrm{CaO} / \mathrm{Al}_{2} \mathrm{O}_{3}$ que disminuye con el $\mathrm{MgO}$ (Figura 8b) y con la falta de anomalía de Eu (Figura 9).

El conjunto mineralógico olivina - clinopiroxeno parece gobernar las primeras etapas en la evolución de la serie, mientras que en una segunda etapa el feldespato alcalino habría jugado un rol importante en la diferenciación de los líquidos más ricos en sílice (Figura 8a y 8b).

Los elementos traza muestran covariaciones lineales positivas fuertes (Figura 10a y 10b) marcando su comportamiento altamente incompatible. La constancia en las concentraciones de los elementos puede asumirse como resultado de procesos de fraccionamiento.

La composición de elementos menores y traza de las distintas facies identificadas se presentan en las Figuras 9 y 11 como diagramas multielementos y de tierras raras.

Los patrones revelan un incremento neto en las concentraciones de las TR con la diferenciación. Los basaltos presentan relaciones $(\mathrm{La} / \mathrm{Yb})_{\mathrm{n}}$ 9-14 en tanto que las rocas diferenciadas oscilan entre 7-18 (Figura 9). Traquitas y riolitas muestran un patrón poco fraccionado para el segmento TRM-TRP que las distingue de los basaltos. Estos presentan dispersión en las concentraciones de TRL con respecto a las TRP interpretada como una variación en la dinámica de la fusión.

El patrón multielemento (Figura 11) de las rocas diferenciadas contrasta con el de los basaltos presentando fuertes anomalías. La marcada anomalía de Eu pone en evidencia el fraccionamiento de feldespatos como proceso de diferenciación y está acompañada por profundas depresiones en Ba, Sr. A su vez se observan empobrecimientos en $\mathrm{P}$ y Ti y enriquecimientos en $\mathrm{Rb}$, Th, Hf y Zr. Si bien Nb y Ta se destaca con valores altos hay un comportamiento diferenciable entre ambos que es más notorio y opuesto en traquitas y riolitas que en los basaltos. El par U-Th se enriquece notablemente en las rocas diferenciadas. Los basaltos se distinguen por anomalías positivas en $\mathrm{Ba}$ y solamente la correspondiente a los derrames nororientales tiene una débil anomalía negativa en $\mathrm{K}$.
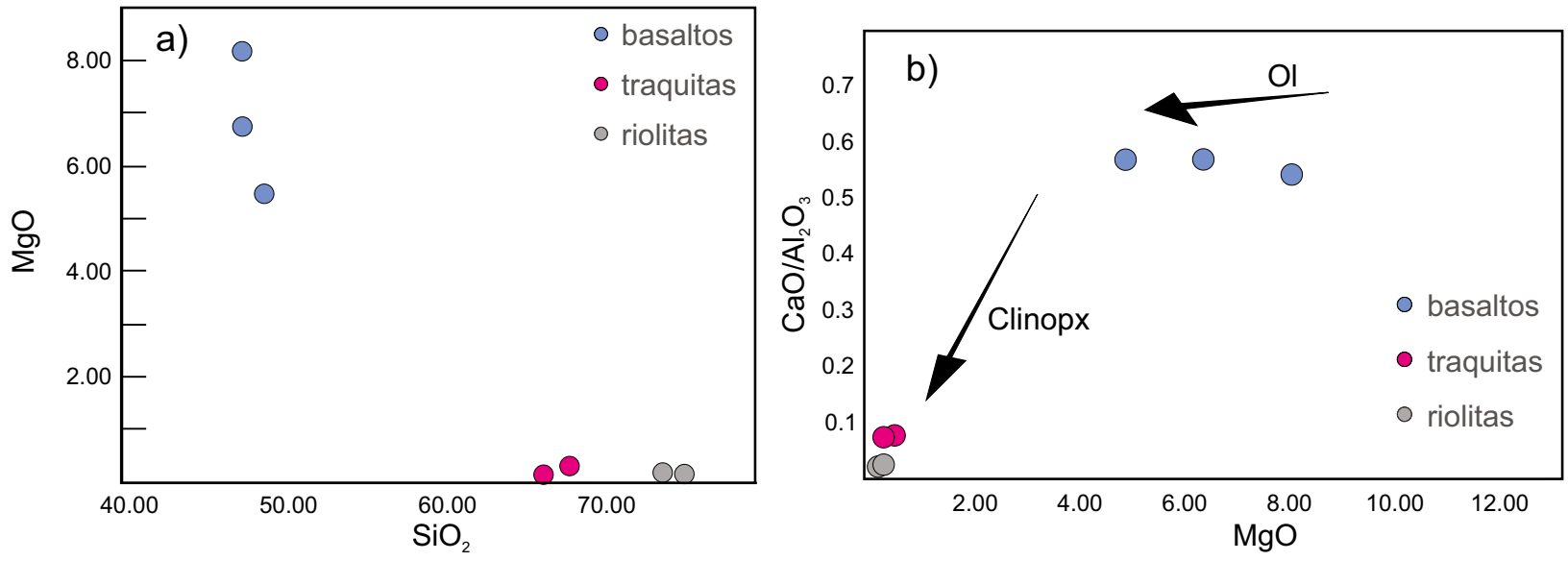

Figura 8. a) El diagrama de variación $\mathrm{MgO}$ versus $\mathrm{SiO}_{2}$ muestra la fuerte tendencia de empobrecimiento en $\mathrm{MgO}$ por cristalización de olivina en las etapas iniciales de la diferenciación de la secuencia y pone en evidencia la importante brecha composicional entre basaltos y rocas diferenciadas. b) El diagrama de covariación $\mathrm{CaO} / \mathrm{Al}_{2} \mathrm{O}_{3}$ versus $\mathrm{MgO}$ corrobora el fraccionamiento de olivina y marca la tendencia de evolución según el fraccionamiento de clinopiroxeno entre basaltos y traquitas-riolitas. 


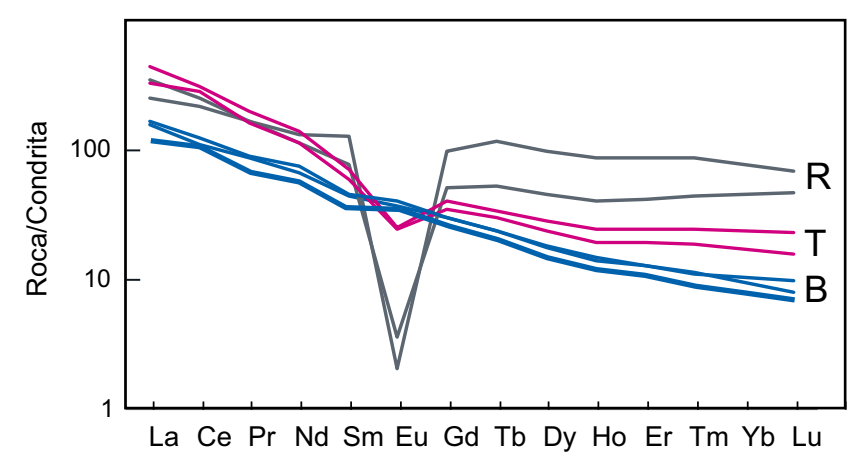

Figura 9. Diagrama de tierra raras para las rocas del Complejo Volcánico Barril Niyeu. Se utilizaron los valores de normalización propuestos por Sun and McDonough (1989). Riolitas (R) (Traquitas (T) y Basaltos (B).

Las rocas de alta sílice suelen tener importantes depresiones en $\mathrm{Sr}$, Ba y Eu. Halliday et al. (1991) proponen que las depresiones en $\mathrm{Sr}$ y Ba se vinculan al fraccionamiento de feldespato alcalino más que de plagioclasa. Por lo cual, si bien no puede descartarse, a la luz de los análisis disponibles, la posibilidad de plagioclasa en el conjunto mineral que se fracciona o incluso de apatita, parece que estos elementos se empobrecen por su compatibilidad en el feldespato alcalino (Henderson and Pierozynski, 2012).

\section{GEOCRONOLOGÍA}

\section{Geocronología U-Pb SHRIMP}

\section{Metodología}

Se procesó menos que $1 \mathrm{~kg}$ de roca para las dos muestras investigadas. Las muestras fueron trituradas, molidas y tamizadas por tamiz malla $60(0.25 \mathrm{~mm})$, lavadas para remover las fracciones limo y arcilla. El material restante, correspondiente a arena fina y muy fina, fue secado y procesado por dos líquidos pesados LST (tungstato litio-sodio, densidad 2.82) y TBE (tetra-bromo-etano, densidad 2.98). El concentrado de minerales pesados fue separado en cuatro fracciones usando separador magnético Frantz $z^{\oplus}$. Utilizando una inclinación de $5^{\circ} \mathrm{y}$ una corriente de 1 ampere de la fracción menos magnética. Luego los cristales de circón se montaron en disco epoxy de $2.5 \mathrm{~cm}$ junto con los estándares analíticos. El montaje fue pulido y cubierto con carbón para para su estudio mediante microscopía electrónica y obtener imágenes con un Microscopio de barrido electrónico TESCAN-VEGA3 en el Centro de Microscopía, Caracterización y Microanálisis de la Universidad de Western Australia. La cubierta de carbón fue removida y reemplazada por una cubierta de oro para análisis U-Pb por SHRIMP.

Los análisis isotópicos $\mathrm{U}-\mathrm{Pb}$ en Sensitive High Resolution Ion MicroProbe (SHRIMP II) se realizaron en la Universidad Curtin en varias sesiones utilizando un área analítica circular de $20-25 \mu \mathrm{m}$ de diámetro. Detalles del procedimiento analítico figuran en De Laeter y Kennedy (1998). Los análisis individuales se componen de 9 mediciones $\left({ }^{196} \mathrm{Zr}_{2} \mathrm{O}\right.$, ${ }^{204} \mathrm{~Pb}$, señal de fondo, ${ }^{206} \mathrm{~Pb},{ }^{207} \mathrm{~Pb},{ }^{208} \mathrm{~Pb}$, ${ }^{238} \mathrm{U}$, ${ }^{248} \mathrm{ThO}$, ${ }^{254} \mathrm{UO}$ ), repetidas en cinco scaneos. Se utilizó el estándar NBS611 para identificar la posición del pico de masa ${ }^{204} \mathrm{~Pb}$, mientras que para la calibración del contenido de $\mathrm{U}$ y la determinación de la relación $\mathrm{Pb} / \mathrm{U}$ ratio se utilizó BR266 (559 Ma, 903 ppm U; Stern, 2001). Debido a la cantidad extremadamente baja de plomo radigénico (promedio $1.12 \mathrm{ppm}$ de ${ }^{206} \mathrm{~Pb}$ y $63 \mathrm{ppb}$ de ${ }^{207} \mathrm{~Pb}$ ) se tomaron las siguientes medidas:

a) La ubicación del pico de masa ${ }^{206} \mathrm{~Pb}$ no fue centrada

b) El tiempo de conteo de ${ }^{206} \mathrm{~Pb}$ se incrementó con respecto al usual de 10 hasta 30 segundos;

c) La cantidad de ${ }^{207} \mathrm{~Pb}$ no se corrigió por la presencia de plomo común. La corrección de plomo común presente en las relaciones ${ }^{206} \mathrm{~Pb} /{ }^{238} \mathrm{U}$ y edades fue hecha usando la cantitad de ${ }^{207} \mathrm{~Pb}$ (en vez de ${ }^{204} \mathrm{~Pb}$ ).

Los datos fueron procesados usando el software SQUID@ 2.50 (Ludwig, 2009) y las edades calculadas usando el software Isoplot@ 3.75 (Ludwig, 2012). Las edades ${ }^{206} \mathrm{~Pb} /{ }^{238} \mathrm{U}$ presentadas están calculadas en el nivel $2 \sigma$ usando el algoritmo TuffZirc (Ludwig, 2012).

\section{Resultados}

La muestra MQ 575, proveniente de Puesto Navarrete, es una traquita con cristales de circón de 150 micrones en promedio que en su mayor parte se encuentran en fragmentos, tienen zonación marcada, (delgada y fina). Los granos son magmáticos, con un contenido promedio de $\mathrm{U}$ de $124 \mathrm{ppm}$ y promedio Th/U de 0.73 Posee un circón heredado con una edad de $560 \pm 9$ Ma y baja relación Th/U=0.057 (Tabla 2).

En la lava riolítica de Puesto Suárez, MQ 570, los circones tienen tamaños entre 80 y 250 micrones, presentan zonación difusa con
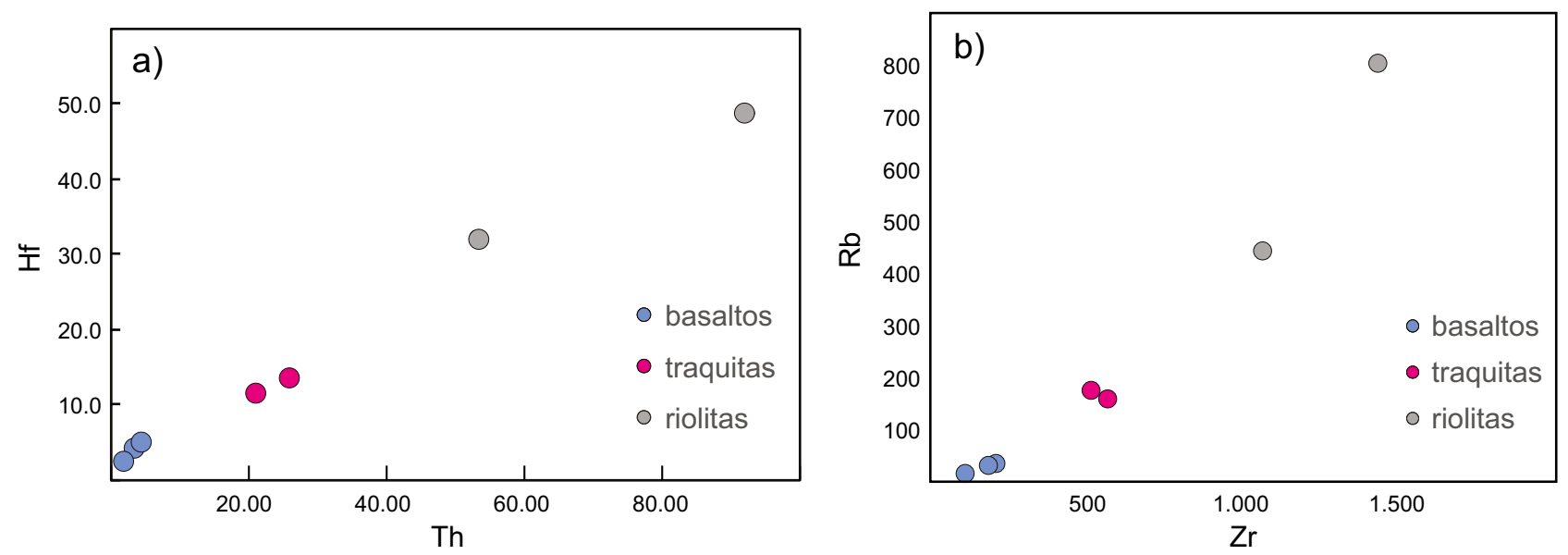

Figura 10. Diagramas de covariación entre elementos incompatibles. a) en el diagrama $\mathrm{Hf} v s$. Th las muestras tienen una distribución que atestigua una incompatibilidad semejante de ambos elementos en la secuencia. b) el diagrama $\mathrm{Rb} v$ s. Zr parece indicar una mayor incompatibilidad del Rb según se desprende de la distribución de valores. 


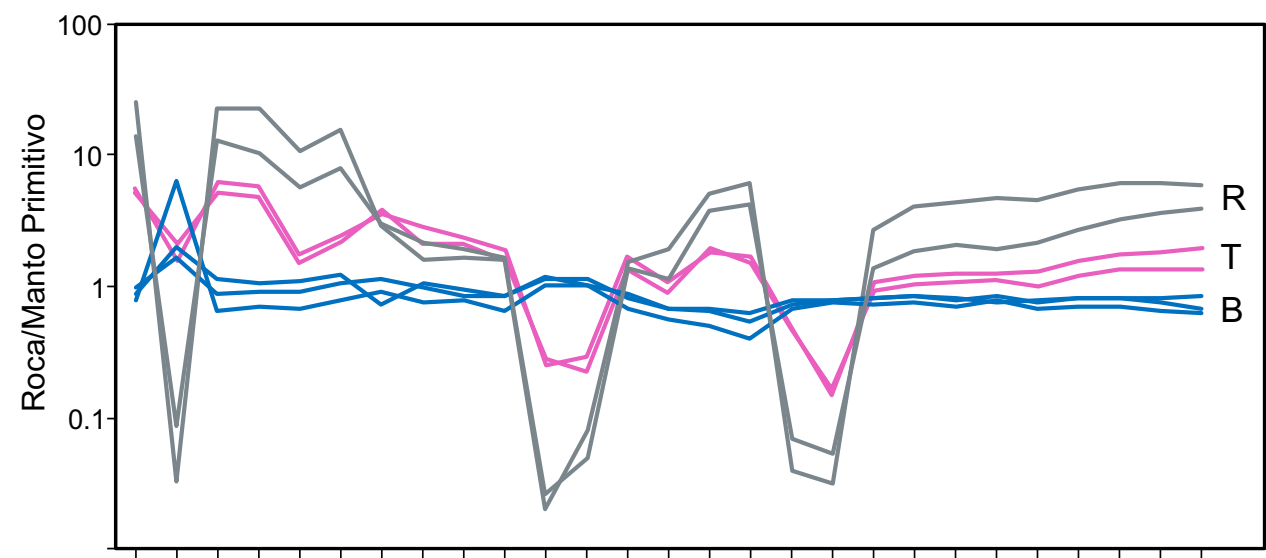

Rb Ba Th Ú Nb Ta K La Ce Pr Sr P Nd Sm Zr Hf Eu Ti Gd Tb Dy Y Ho Er Tm Yb Lu

Figura 11. Diagrama multielementos para elementos traza normalizados a los valores del Manto Primitivo según la propuesta de Sun and McDonough (1989). Riolitas (R), Traquitas (T), Basaltos (B).

zonas amplias. En general, muestran formas redondeadas hecho que se atribuye a procesos de reabsorción magmática; algunos ejemplares conservan las formas euhedrales (Figura 12). Los circones son magmáticos, con un contenido promedio de $\mathrm{U}$ de $403 \mathrm{ppm}$, y promedio $\mathrm{Th} / \mathrm{U}$ de 1.00 (Tabla 2).

Se han determinado dos circones heredados que presentan una edad paleocena $56.9 \pm 1 \mathrm{Ma} \mathrm{Th} / \mathrm{U}$ de 1.07 (F.3-2) y otra cámbrica $500 \pm 9 \mathrm{Ma}$ y con Th/U de 0.70 (F7-1).

En el caso de la muestra MQ575 la edad fue determinada a partir de 10 granos y es de $32.32+0.48-0.98$ Ma y para la MQ570 se utili- zaron 10 de 12 granos resultando una edad de $32.01+0.51-0.34 \mathrm{Ma}$ correspondiendo al Oligoceno Tardío-Rupeliano (Figura13).

\section{Geocronología K-Ar}

Metodología y resultados

Un basalto correspondiente a las erupciones periféricas del complejo, que cubre el sector noreste, fue datado por el método K-Ar sobre roca total en los Laboratorios Actlabs, Canadá. Para la

Tabla 2. Datos isotópicos U-Pb de circones de las muestras 575 ( $\left.41^{\circ} 40^{\prime} 31^{\prime \prime S} ; 68^{\circ} 55^{\prime} 26^{\prime \prime O}\right)$ y $570\left(41^{\circ} 38^{\prime} 04^{\prime \prime} \mathrm{S} ; 68^{\circ} 52^{\prime} 28^{\prime \prime O}\right)$.

\begin{tabular}{|c|c|c|c|c|c|c|c|c|c|c|c|c|c|c|c|c|c|}
\hline Spot & $\begin{array}{c}\mathrm{U} \\
(\mathrm{ppm})\end{array}$ & $\begin{array}{c}\text { Th } \\
\text { (ppm) }\end{array}$ & $\begin{array}{l}{ }^{232} \mathrm{Th} / \\
{ }^{238} \mathrm{U}\end{array}$ & $\begin{array}{c}\text { 7-corr } \\
\text { ppm } \\
{ }^{206} \mathrm{~Pb}\end{array}$ & $\begin{array}{l}\text { 7-corr } \\
\% \text { com } \\
{ }^{206} \mathrm{~Pb}\end{array}$ & $\begin{array}{c}\text { 7-corr } \\
{ }^{206} \mathrm{~Pb} / \\
{ }^{238} \mathrm{U}\end{array}$ & $\begin{array}{c}\% \\
\text { err }\end{array}$ & $\begin{array}{c}\text { Uncorr. } \\
{ }^{207} \mathrm{~Pb} / \\
{ }^{206} \mathrm{~Pb}\end{array}$ & $\begin{array}{c}\% \\
\text { err }\end{array}$ & $\begin{array}{c}\text { 7-corr } \\
{ }^{238} \mathrm{U} / \\
{ }^{206} \mathrm{~Pb}\end{array}$ & $\begin{array}{c}\% \\
\text { err }\end{array}$ & $\begin{array}{l}\text { 7-corr } \\
{ }^{208} \mathrm{~Pb} / \\
{ }^{232} \mathrm{Th}\end{array}$ & & $\begin{array}{c}207 \text { corr } \\
{ }^{206} \mathrm{~Pb} /{ }^{238} \mathrm{U} \\
\text { Age }\end{array}$ & $\begin{array}{l}1 s \\
\text { err }\end{array}$ & $\begin{array}{c}204 \text { corr } \\
{ }^{206} \mathrm{~Pb} /{ }^{238} \mathrm{U} \\
\text { Age }\end{array}$ & $\begin{array}{l}1 s \\
\text { err }\end{array}$ \\
\hline \multicolumn{18}{|c|}{ MQ575, Traquita } \\
\hline 1321G.1-1 & 154 & 120 & 0.81 & 0.59 & 3.35 & 0.00500 & 0.78 & 0.07314 & 13.92 & 199.9516 & 0.78 & 0.0016 & 20.12 & 32.2 & 0.8 & 28.5 & 1.9 \\
\hline 1321G.2-1 & 86 & 52 & 0.62 & 0.37 & 4.03 & 0.00503 & 1.24 & 0.07856 & 17.90 & 198.9377 & 1.24 & 0.0017 & 21.28 & 32.3 & 1.3 & 32.4 & 1.7 \\
\hline 1321G.3-1 & 95 & 63 & 0.69 & 0.36 & 2.65 & 0.00500 & 0.86 & 0.06764 & 20.06 & 199.9537 & 0.86 & 0.0018 & 17.41 & 32.2 & 0.9 & 27.9 & 2.3 \\
\hline 1321G.4-1 & 68 & 44 & 0.66 & 0.27 & 11.99 & 0.00510 & 2.84 & 0.14155 & 25.92 & 195.9903 & 2.84 & 0.0011 & 84.19 & 32.8 & 2.9 & 29.4 & 4.1 \\
\hline 1321G.4-2 & 121 & 76 & 0.64 & 0.47 & 1.14 & 0.00516 & 0.78 & 0.05573 & 19.48 & 193.6423 & 0.78 & 0.0015 & 17.59 & 33.2 & 0.8 & 29.0 & 2.1 \\
\hline 1321G.4-3 & 190 & 110 & 0.60 & 0.83 & 2.32 & 0.00487 & 1.12 & 0.06497 & 13.89 & 205.2053 & 1.12 & 0.0014 & 20.28 & 31.3 & 1.1 & 32.5 & 1.2 \\
\hline $1321 G .4-4$ & 164 & 187 & 1.18 & 0.67 & 0.98 & 0.00504 & 1.19 & 0.05445 & 18.77 & 198.4065 & 1.19 & 0.0018 & 9.43 & 32.4 & 1.2 & 30.6 & 1.6 \\
\hline $1321 \mathrm{G} .4-5$ & 511 & 28 & 0.057 & 39.81 & 0.12 & 0.09067 & 0.58 & 0.05976 & 1.15 & 11.0268 & 1.79 & 0.0242 & 15.86 & 559.5 & 9.8 & 560.1 & 9.7 \\
\hline 1321G.5-1 & 99 & 60 & 0.63 & 0.43 & 5.39 & 0.00476 & 1.71 & 0.08922 & 17.06 & 210.1704 & 1.71 & 0.0007 & 48.83 & 30.6 & 1.6 & 32.1 & 1.6 \\
\hline 1321G.5-2 & 179 & 148 & 0.85 & 0.77 & 1.57 & 0.00505 & 0.75 & 0.05906 & 15.33 & 197.8598 & 0.75 & 0.0016 & 11.21 & 32.5 & 0.8 & 32.3 & 0.9 \\
\hline 1321G.8-1 & 93 & 62 & 0.68 & 0.34 & 2.81 & 0.00524 & 0.82 & 0.06890 & 19.81 & 190.6660 & 0.82 & 0.0021 & 14.82 & 33.7 & 0.9 & 27.6 & 2.4 \\
\hline \multicolumn{18}{|l|}{ MQ570, Riolita } \\
\hline 1319F.2-1-2 & 305 & 370 & 1.25 & 1.28 & 0.00 & 0.00485 & 2.19 & 0.04966 & 12.89 & 206.3893 & 2.19 & 0.0015 & 5.31 & 31.2 & 0.7 & 31.3 & 0.6 \\
\hline 1319F.2-2 & 323 & 331 & 1.06 & 1.40 & 0.00 & 0.00499 & 2.06 & 0.05433 & 10.86 & 200.4467 & 2.06 & 0.0015 & 5.68 & 32.1 & 0.7 & 32.4 & 0.6 \\
\hline 1319F.3-1-45 & 92 & 58 & 0.64 & 0.39 & 0.00 & 0.00483 & 4.01 & 0.07047 & 25.23 & 206.9170 & 4.01 & 0.0016 & 15.49 & 31.1 & 1.2 & 32.0 & 1.1 \\
\hline 1319F.3-2 & 383 & 396 & 1.07 & 2.98 & 2.16 & 0.00061 & 29.52 & 1.08841 & 1.90 & 112.7973 & 1.82 & 0.1388 & 1.97 & 3.9 & 1.2 & 56.9 & 1.0 \\
\hline 1319F.3-3 & 360 & 198 & 0.57 & 1.54 & 0.00 & 0.00489 & 2.03 & 0.06130 & 9.88 & 204.4439 & 2.03 & 0.0016 & 6.04 & 31.5 & 0.6 & 32.0 & 0.6 \\
\hline 1319F.4-1 & 876 & 1428 & 1.68 & 3.81 & 0.00 & 0.00506 & 1.54 & 0.04767 & 5.70 & 197.5612 & 1.54 & 0.0016 & 2.34 & 32.5 & 0.5 & 32.6 & 0.5 \\
\hline 1319.F-4-2 & 334 & 284 & 0.88 & 1.44 & 0.00 & 0.00498 & 2.03 & 0.05528 & 10.39 & 200.9621 & 2.03 & 0.0016 & 5.13 & 32.0 & 0.6 & 32.3 & 0.6 \\
\hline 1319F.5-1 & 334 & 277 & 0.86 & 1.42 & 0.00 & 0.00489 & 1.88 & 0.05373 & 9.51 & 204.5554 & 1.88 & 0.0015 & 4.61 & 31.4 & 0.6 & 31.7 & 0.6 \\
\hline 1319F.6-1 & 630 & 746 & 1.22 & 2.61 & 0.00 & 0.00481 & 1.79 & 0.04911 & 8.16 & 207.9591 & 1.79 & 0.0016 & 3.45 & 30.9 & 0.6 & 31.0 & 0.5 \\
\hline 1319F.6-2 & 523 & 506 & 1.00 & 2.24 & 0.00 & 0.00496 & 1.92 & 0.05112 & 8.60 & 201.7331 & 1.92 & 0.0014 & 4.21 & 31.9 & 0.6 & 32.1 & 0.6 \\
\hline 1319F.7-1 & 70 & 47 & 0.70 & 4.87 & 1.84 & 0.08071 & 1.95 & 0.04847 & 14.61 & 12.3893 & 1.95 & 0.0207 & 9.58 & 500.4 & 9.4 & 495.1 & 9.6 \\
\hline 1319F.7-2 & 254 & 213 & 0.87 & 1.10 & 0.00 & 0.00503 & 2.22 & 0.05206 & 13.87 & 198.7887 & 2.22 & 0.0017 & 5.89 & 32.3 & 0.7 & 32.6 & 0.7 \\
\hline
\end{tabular}


determinación de la concentración de $\mathrm{K}$ una alícuota de la muestra se pondera en crisol de grafito con fundente metaborato / tetraborato de litio y fundido utilizando un horno de inducción LECO. La perla de fusión se disuelve con ácido. Los estándares, patrones y la muestra se analizaron en un espectrómetro ICP. El análisis de argón se realizó utilizando el procedimiento de dilución de isótopos en espectrómetro de masas de gas noble.

La edad obtenida, 24.4 Ma (Tabla 3), Oligoceno Tardío- Chattiano, es contemporánea con el basalto Loma Larga de la Sierra de Apas, y resulta poco más antiguo que otras erupciones basálticas relacionadas a complejos bimodales estudiados dentro de la asociación magmática de Somún Curá, los cuales en general promedian 18-20Ma.

\section{DISCUSIÓN}

El CVAP integra la Provincia Magmática Somún Curá junto con los complejos volcánicos de Alta Sierra de Somún Curá, Apas, Barril Niyeu, Pire Mahuida, Sierra Negra de Telsen, Sierra de Los Chacays y Talagapa.

La mayoría de los grandes complejos bimodales dentro de la Provincia Magmática Somún Curá están alineados a lo largo de una faja de orientación ONO-ESE, definida como una megaestructura (Salani et al., 2010 y Remesal et al., 2012) que favoreció el magmatismo post meseta.

El CVAP se encuentra en el sector más occidental de esta estructura en el límite de la meseta basáltica de Somún Curá. Remesal et al. $(2004,2012)$ y Salani et al. (2006) mencionan una asociación litológica semejante en distintos complejos, representada por una secuencia general que inicia con una facies eruptiva ácida, lavas y flujos piroclásticos y culmina con facies basálticas. Sin embargo, existen ligeras diferencias, por ejemplo en el CVAP los flujos piroclásticos fueron caracterizados como flujos piroclásticos traquíticos mientras que en otros complejos tienen composiciones mayoritariamente riolíticas (Pire Mahuida, Barril Niyeu; Remesal et al., 2012, Salani, 1990). Los flujos y domos traquíticos y los basaltos son comparables en los distintos complejos volcánicos.

Petrográfica y químicamente la secuencia del CVAP es alcalina. Las rocas traquíticas presentan sanidina, anortoclasa y aegirina y los basaltos olivina y augita titanífera. Una brecha composicional ha sido

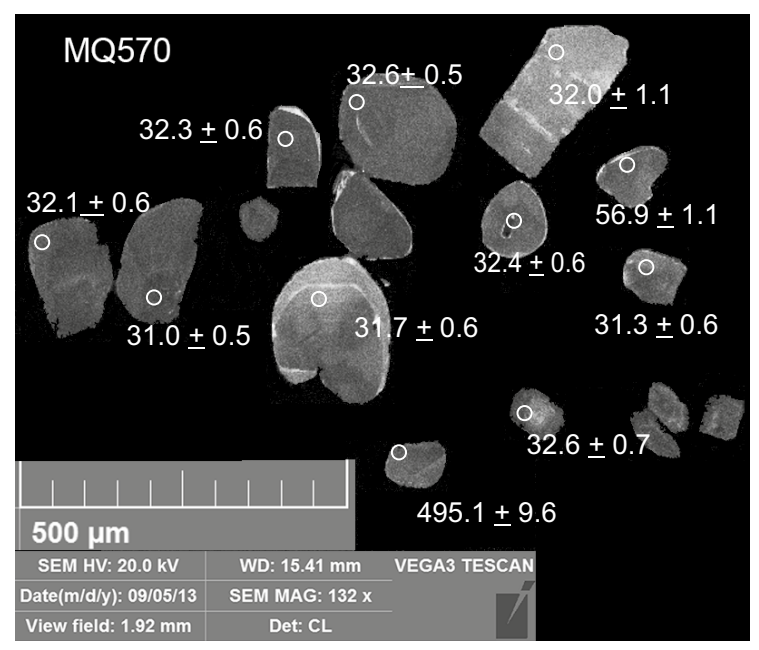

Figura 12.Imagen de catodoluminiscencia mostrando los circones analizados en la muestra MQ 570. detectada como característica en la geoquímica de la mayoría de los complejos en el contexto de la provincia magmática.

El proceso de cristalización fraccionada en un sistema magmático puede evaluarse a través de gráficos de covariación de elementos traza incompatibles con enriquecimiento como en el caso de la secuencia analizada (Figura 10). El conjunto de fraccionamiento estaría representado por olivina y clinopiroxeno en los tramos de basalto a traquita y feldespatos en la parte más evolucionada de la serie.

Sin embargo, la cristalización fraccionada no es el único proceso cristal líquido que define tendencias lineales. Por este motivo no se descartan otros procesos que podrían corroborarse con estudios más específicos (isótopos, balance de masas). La información geoquímica disponible no aporta evidencias sobre procesos de asimilación cortical y es limitada para explorar los posibles controles de fuente y de cámara de estas rocas. En este sentido, Remesal et al. (2012) presentaron relaciones isotópicas para el Complejo Volcánico Barril Niyeu, emplazado en el sureste de Agua de la Piedra dentro de la Provincia Magmática Somún Curá, a partir de las cuales sugieren una asociación consanguínea y descartan la participación de rocas de la corteza superior en la línea evolutiva de la serie.

Una de las principales discusiones sobre la asociación magmática de Somún Curá, es la referida al rango temporal durante el cual se extendieron las efusiones que construyeron este gran campo volcánico. El evento basáltico, que originó la meseta de Somún Curá se habría desarrollado principalmente en el Oligoceno, a partir de los $33 \mathrm{Ma}$ (Ardolino y Franchi, 1993); Ardolino (1981) propone dos picos de efusividad, uno entre los 33 y 31 Ma y otro entre los 27 y $25 \mathrm{Ma}$. Este último coincide con el determinado por Remesal (1988) y Orgeira y Remesal (1993) entre 26 y $27 \mathrm{Ma}$. El conocimiento de la edad del vulcanismo post meseta (complejos bimodales y centros monogenéticos) se basa mayormente en determinaciones $\mathrm{K}-\mathrm{Ar}$ y $\mathrm{Rb}$-Sr y las edades $\mathrm{U}-\mathrm{Pb}$ publicadas recientemente para el Complejo Volcánico Pire Mahuida (Salani y Santos, 2014, Salani et al., 2014, Tabla 4) y el Complejo de la Sierra de los Chacays (Cordenons et al., 2014, Tabla 4).

El conjunto de edades del volcanismo post-meseta indica un pico de actividad en el Mioceno temprano.

Los estudios realizados en el CVAP (Remesal et al., 2001) establecieron con base en la similitud litológica y los patrones de evolución con otros complejos, que este vulcanismo fue sincrónico a las efusiones post-meseta del Mioceno.

Sin embargo, las nuevas edades obtenidas son más antiguas que las esperadas. Los dos flujos traquíticos datados tienen edades de 32.41 $+0.80-0.25 \mathrm{Ma}$ y $31.88+0.47-0.80 \mathrm{Ma}$. Un ejemplar de traquita del Complejo fechado por K-Ar sobre roca total dio una edad (31.7 $\pm 0.9 \mathrm{Ma})$ consistente con estos resultados (Remesal y Salani, 2018, Tabla 4). Cuando se compara las edades obtenidas para el CVAP con el resto de las asociaciones post meseta, es evidente que el CVAP representa uno de los complejos más antiguos de la Provincia Magmática Somún Curá. Resultados geocronológicos recientemente publicados (Tabla 4) indican que el Complejo Volcánico Sierra de los Chacays (CVSCH) también corresponde a un episodio de emplazamiento temprano respecto de otros complejos. Particularmente estos dos complejos se disponen en sectores marginales de la meseta, el CVAP en el extremo oeste y el CVSCH en el extremo sudeste (Figura 1).

De acuerdo a los datos disponibles de las rocas félsicas, se interpreta que las efusiones traquíticas y riolíticas serían poco posteriores o coetáneas con las primeras etapas del magmatismo de meseta. Los basaltos de Agua de la Piedra cubren a los cuerpos traquíticos, la edad determinada por K-Ar de $24.4 \pm 0.9$ indica que podrían ser sincrónicos con los eventos basálticos miocenos de otros complejos bimodales (Basalto Loma Larga del Complejo de la Sierra de Apas, Tabla 4) y los de centros basálticos monogenéticos (cerro dos Hermanos). 

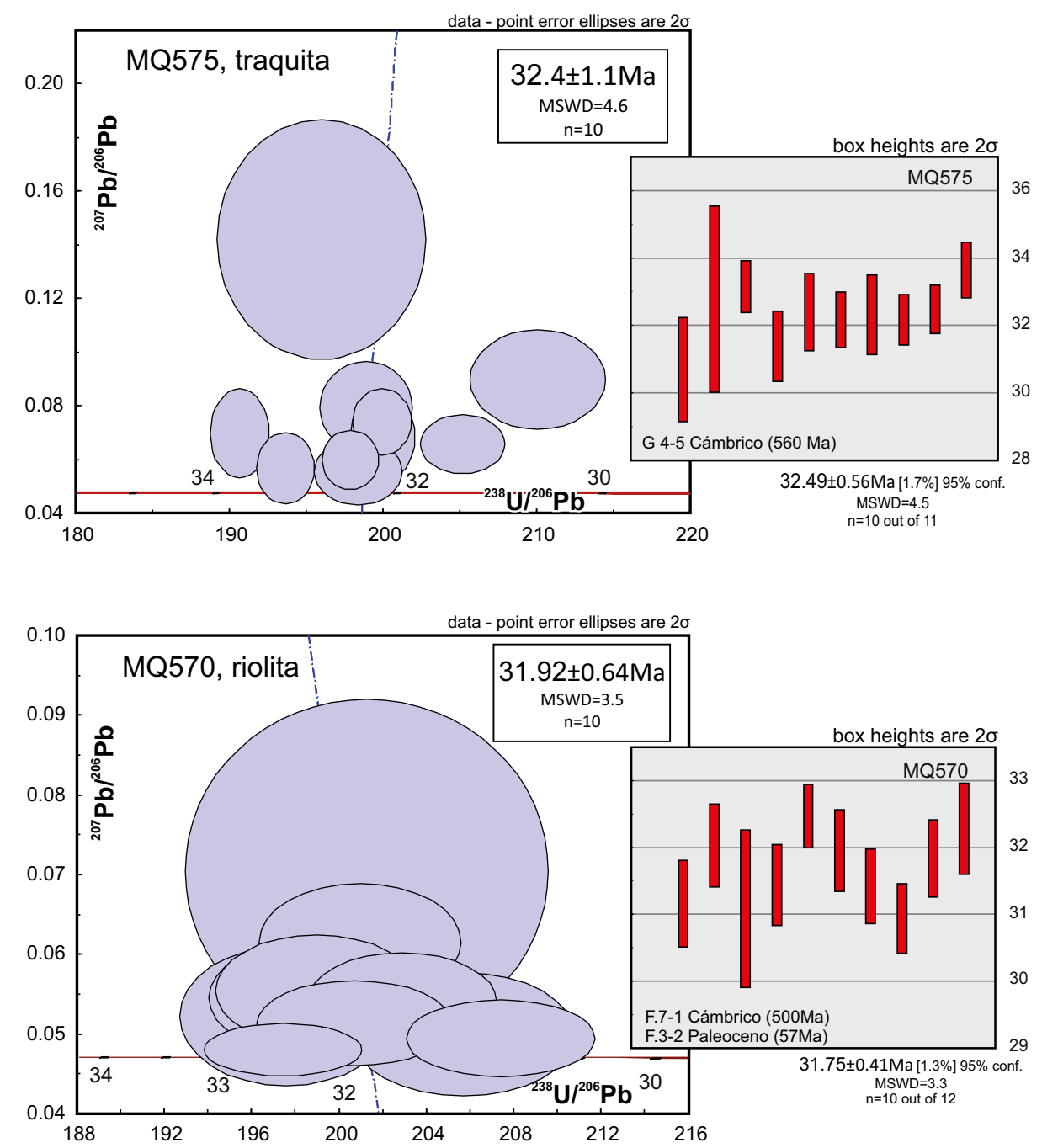

Figura 13. Diagramas de concordia inversa $\left({ }^{207} \mathrm{~Pb} / 206 \mathrm{~Pb}\right.$ ss. $206 \mathrm{~Pb} / 238 \mathrm{U}$ ) de edades de circones magmáticos de las muestras analizadas (edades concordia: $32.4 \pm 1.1 \mathrm{Ma}$ y $31.92 \pm 0.64 \mathrm{Ma}$ y edades media de los mismos circones analizados $(32.49 \pm 0.56$ y $31.75 \pm 0.41 \mathrm{Ma})$.

Las volcanitas presentan circones magmáticos heredados tanto del Paleoceno (56.9 $\pm 1 \mathrm{Ma})$ como así también herencias más antiguas de $495 \pm 9.6 \mathrm{Ma}$ (Cámbrico Serie 2) y $560 \pm 9.7 \mathrm{Ma}$ (Neoproterozoico, Ediacariano).

En cuanto a la herencia más joven encontrada en la lava riolítica de Puesto Suárez, corresponde a un circón que presenta una relación $\mathrm{Th} / \mathrm{U}$ de 1.07 coherente con un origen magmático. Con respecto a la posible procedencia se debe mencionar que, en proximidades del Complejo Agua de la Piedra, y rodeando al núcleo de la sierra afloran una serie de cuerpos ígneos atribuidos a un evento paleógeno inferior de amplia distribución en el ambiente patagónico extrandino. Este evento agrupa un magmatismo alcalino mesosilícico a básico principalmente subvolcánico. En el área se encuentra representado por la Formación Cerro Cortado definida por Nullo (1978), y sus equivalentes El Buitre
(Ardolino y Franchi, 1993) y El Canquel (Lema y Cortés, 1987).

Este magmatismo fue datado en diversas localidades de la Patagonia, mediante K-Ar en roca total (Nullo, 1978; Coira, 1979; Coira et al., 1985; Lema y Cortés, 1987; Linares y González, 1990; Ardolino y Franchi, 1993; Vietto y Bitschene, 1994; Ardolino et al., 1995; Chelotti et al., 1996; Salani et al., 2001), con un rango de edades entre el Paleoceno y el Eoceno; el pico de actividad parece corresponder al Eoceno temprano, perdurando hasta el Eoceno medio, con edades comprendidas entre $58 \pm 5$ y $40 \pm 5 \mathrm{Ma}$.

Se interpreta que los cuerpos mesosilícicos más antiguos de la Formación Cerro Cortado habrían sido la fuente local del circón de la riolita de Puesto Suárez.

En cuanto a las herencias más antiguas, regionalmente se conoce con precisión la edad de cristalización de una unidad cámbrica

Tabla 3. Determinación analítica, edad K-Ar sobre roca total en basalto del CVAP. Laboratorios de Actlabs, Canadá.

\begin{tabular}{cccccc}
\hline Muestra & Ubicación & ${ }^{40} \mathrm{Ar} \mathbf{~ r a d},(\mathrm{nl} / \mathrm{g})$ & \%K & ${ }^{40} \mathrm{Ar}$ aire & Edad (Ma) \\
\hline MQ-596 & $41^{\circ} 33^{\prime} 47^{\prime \prime}$ S; 68 $50^{\circ} 36^{\prime \prime} \mathrm{O}$ & 0.93 & 0.99 & 74.1 & $24.4 \pm 0.9$ \\
\hline
\end{tabular}


Tabla 4. Edades K-Ar y U-Pb de asociaciones post meseta dentro de la provincia magmática Somún Curá.

\begin{tabular}{lcccl}
\hline Localidad & Método & Roca & Edad (Ma) & Referencias \\
\hline Sierra de Apas & K/Ar Roca total & Basalto & $23 \pm 2$ & Ardolino, 1981 \\
Sierra de Apas & K/Ar Roca total & Traquita & $19 \pm 2$ & Remesal et al., 2004 \\
Sierra de Talagapa & K/Ar Roca total & Basalto & $19 \pm 1$ & Ardolino, 1981 \\
Sierra de Talagapa & K/Ar Roca total & Basalto & $20 \pm 1$ & Ardolino, 1981 \\
Sierra de Telsen & K/Ar Roca total & Basalto & $17 \pm 1$ & Ardolino, 1981 \\
Trayén Niyeu & K/Ar Roca total & Basalto & $18.8 \pm 0.5$ & Salani et al., 2006 \\
Dos Hermanos Hill & K/Ar Roca total & Basalto & $22.5 \pm 0.9$ & Salani et al., 2006 \\
SierraChauchauiñeu & K/Ar Roca total & Traquita & $20.6 \pm 0.4$ & Remesal et al., 2012 \\
Sierra Chauchauiñeu & K/Ar Roca total & Basalto & $18.7 \pm 0.4$ & Remesal et al., 2012 \\
Sierra Pire Mahuida & U-Pb-Th Circon & Riolita & $16.85+0.07-0.21$ & Salani y Santos, 2014 \\
Sierra Pire Mahuida & U-Pb-Th Circon & Riolita & $17.62+0.56-0.15$ & Salani et al., 2014 \\
Sierra de Los Chacays & U-Pb-Th Circon & Traquita & $24.87+0.57-0.21$ & Cordenons et al., 2014 \\
Sierra Agua de La Piedra & K/Ar Roca total & Traquita & $31.7 \pm 0.9$ & Remesal y Salani, 2018 \\
\hline
\end{tabular}

inferior (Granodiorita Tardugno; Chernicoff y Caminos, 1996) datada en $522.8 \pm 2.1 \mathrm{Ma}$ (Chernicoff et al., 2013) a $528.5 \pm 3.5$ (Rapalini et al., 2013), en este último caso con circones heredados de ca. $610 \mathrm{Ma}$.

Asimismo, los picos dominantes de los circones detríticos de las unidades metasedimentarias Formación Nahuel Niyeu y Formación El Jagüelito constituyen una evidencia, si bien más indirecta, de la ocurrencia de un sustrato magmático cámbrico en la región. La unidad metasedimentaria Formación Nahuel Niyeu, de edad ordovícica inferior (edad de los circones más jóvenes 482-490 Ma), tiene un pico dominante de ca. $515 \mathrm{Ma}$ (Pankhurst et al., 2006), y su equivalente en la región atlántica, Formación El Jagüelito -levemente más antigua (edad del circón más joven ca. 510 Ma; Cámbrico serie 2) - presenta un pico de ca. 523-538 Ma (Naipauer et al., 2010; Pankhurst et al., 2006; González et al., 2018).

Se debe destacar que la Granodiorita Tardugno, fue interpretada como un magmatismo de arco, un remanente del arco magmático de Ross (Chernicoff et al., 2013; González et al., 2018) o una extensión del arco magmático pampeano (Rapalini et al., 2013).

La baja relación $\mathrm{Th} / \mathrm{U}=0.057$ que presenta el circón $\mathrm{G} 4-5$ de la muestra MQ $575(560.1 \pm 9.7)$ indica una herencia metamórfica (Vavra et al., 1999). Por el contrario, el circón heredado presente en la traquita MQ570 tiene una relación $\mathrm{Th} / \mathrm{U}=0.70$ en el rango de los cristales magmáticos (Hartmann y Santos, 2004).

Los circones más antiguos presentes en las volcanitas del Complejo Agua de La Piedra sugieren la asimilación de material de los granitoides de arco de edades neoproterozoicas y cámbricas. Sin embargo, esta asimilación no se refleja en las evidencias geoquímicas disponibles.

\section{CONCLUSIONES}

El Complejo Volcánico Agua de la Piedra constituye una asociación bimodal traquítica/riolitica - basáltica emplazada en el sector centrosur de la provincia de Río Negro, en el ámbito del Macizo de Somún Curá. Cubre rocas de las formaciones Angostura Colorada y Coli Toro y del Grupo Sarmiento.

La petrografía de la asociación (con feldespatos alcalinos, augita titanífera, biotita rica en $\mathrm{Ti}$, aegirina y arfvedsonita) define una serie alcalina corroborada por la geoquímica de sus elementos mayores y traza. La composición de esta serie es basáltico-traquítica y alcanza el extremo riolítico. El vulcanismo de CVAP es una asociación bimodal con una brecha entre 52 y $66 \mathrm{SiO}_{2} \%$ por peso. Las tendencias geoquímicas sugieren que la evolución estaría controlada por el fraccionamiento de clinopiroxeno y olivina en los estadios iniciales y a partir de las composiciones traquíticas por feldespatos. No existen evidencias geoquímicas que permitan establecer procesos de asimilación cortical.

Las características litológicas, morfología, rasgos químicos y relaciones estratigráficas vinculan este magmatismo con otras secuencias post meseta de Somún Curá (Apas, Talagapa y Barril Niyeu, etc.), y permiten integrarlo a la Superunidad Quiñelaf. Particularmente se han encontrado rasgos comparables entre la geoquímica de las rocas más evolucionadas de la sierra de Chauchaiñeu y de Apas (Facies Traquitas Claras).

Las edades determinadas para la facies ácida del Complejo Agua de La Piedra $32.41+0.80-0.25 \mathrm{Ma}$ (Oligoceno tardío-Rupeliano) y $31.88+0.47-0.80 \mathrm{Ma}$ (Oligoceno tardío-Rupeliano) resultan ser más antiguas que las halladas en otras asociaciones bimodales asociadas a la meseta de Somún Curá.

A partir de estos datos surge la necesidad de replantear la cronología de los eventos ácidos y mesosilícicos con respecto a la edad de formación de la meseta. A esta latitud la construcción de los complejos bimodales inicia en el sector occidental en el Oligoceno representado por el magmatismo de Agua de la Piedra y continúa en sectores más orientales del antepaís durante el Mioceno conformando las etapas iniciales de los complejos bimodales Pire Mahuida y Barril Niyeu.

La edad determinada en basaltos del Complejo 24.4 \pm 0.9 (Oligoceno tardío- Chattiano) es coherente con los datos de flujos de basaltos de otras asociaciones (Tabla 4) y sugiere su contemporaneidad con los eventos basálticos miocenos de otros complejos bimodales.

Los circones heredados que presentan las traquitas del CVAP provendrían de cuerpos sulvolcánicos paleógenos de la Formación El Buitre y los de edades más antiguas de un arco magmático NeoproterozoicoCámbrico de acuerdo a las edades reveladas por circones magmáticos y detríticos de distintas unidades del basamento del área patagónica.

\section{AGRADECIMIENTOS}

Este trabajo es una contribución al proyecto UBACYT 20020130100650BA, CONICET PIP 11220130100579 CO. Los análisis de zircón fueron realizados en espectrómetro de masa de alta resolu- 
ción Sensitive High Resolution Ion Micro Probe mass spectrometer (SHRIMP II) en el Centro John de Laeter, Curtin University, con el financiamiento del Consejo de Investigaciones Australiano, (Australian Research Council and Auscope NCRIS). Agradecemos especialmente las sugerencias de los revisores que han enriquecido el presente trabajo.

\section{REFERENCIAS}

Ardolino, A.A., 1981, El vulcanismo cenozoico del borde suroriental de la meseta de Somún Curá. Provincia del Chubut, en VIII Congreso Geológico Argentino, San Luis: Buenos Aires, Asociación Geológica Argentina, I, 65 y III, 7-23.

Ardolino, A., Franchi, M., 1993, El vulcanismo cenozoico de la meseta de Somún Curá, provincias de Río Negro y Chubut, en Actas del XIII Congreso Geológico Argentino y II Congreso de Exploración de Hidrocarburos, IV: Mendoza, Argentina, Asociación Geológica Argentina, 225-235.

Ardolino, A.A., Busteros, A., Cucchi, R., Franchi, M., Lema, H., Remesal, M., 1995. Cuerpos alcalinos básicos paleógenos del sur de Somún Curá (Argentina) y su marco estratigráfico: Ameghiniana, Asociación Paleontológica Argentina, Publicación Especial No. 3, 7-22.

Bertels, A., 1969, Estratigrafía del límite Cretácico-Terciario en Patagonia septentrional: Revista Asociación Geológica Argentina, 24(1), 41-54.

Chelotti, L. A., Vietto, M. E., Calegari, R. J., Bitschene, P.R., 1996, Emplazamiento de cuerpos subvolcánicos de composición básica alcalina en el área Romberg- Wenceslao, cuenca Golfo San Jorge, Argentina, en Actas del XIII Congreso Geológico Argentina y III Congreso de Exploración de Hidrocarburos, III: Buenos Aires, Argentina, Asociación Geológica Argentina, 581-599.

Coira, B., 1979, Descripción Geológica de la Hoja 40d, Ingeniero Jacobacci, provincia de Río Negro: Servicio Geológico Nacional, Boletín 168, 102 pp.

Coira, B., Franchi, M., Nullo, F., 1985, Vulcanismo terciario al oeste de Somuncura y su relación con el arco magmático de la Cordillera Nortpatagónica, Argentina, en Actas $4^{\circ}$ Congreso Geológico Chileno: Antofagasta, Chile, Departamento de Geociencias, Universidad del Norte, III, 468-488.

Cordenons, P.D., Santos, J.O.S., Salani, F.M., 2014, First Zircon U-Th-Pb Shrimp Ages of The Felsic Alkaline Magmatism of the Sierra de Los Chacays Volcanic Complex, Patagonia, Argentina, in 9th South American Symposium on Isotope Geology: Sao Paulo, Brazil, Instituto de Geociencias, Universidad de San Pablo, 182.

De Laeter Jr., Kennedy, A.K., 1998, A double focusing mass spectrometer for geochronology: International Journal Mass Spectrometry, 178, 43-50.

Chernicoff, C.J., Caminos, R., 1996, Estructura y metamorfismo del Complejo Yaminué, Macizo Nordpatagónico, Provincia de Río Negro: Revista de la Asociación Geológica Argentina, 51(2), 107-118.

Chernicoff, C.J., Zappettini, E.O., Santos, J.O.S., 2013, Ross magmatic arc exposed in eastern Patagonia?, en Geosur 2013: Viña del Mar, Chile, Istituto Nazionale di Oceanografia e di Geofisica Sperimentale, 291-292..

Franchi, M., Ardolino, A.A., Remesal, M.B., 2001 , Hoja Geológica 4166-III, Cona Niyeu. Provincia de Río Negro: Buenos Aires, Argentina, Instituto de Geología y Recursos Minerales, Servicio Geológico Minero Argentino. Boletín 262, 1-114.

González, P., Franchi, M., Coluccia, A., 2011, Hoja Geológica 4166-IV, Ingeniero Jacobacci: Buenos Aires, Argentina, Servicio Geológico Minero Argentino, inédito, $94 \mathrm{pp}$.

González, P. D., Sato, A. M., Naipauer M., Varela, R., Basei, M., Sato, K., Llambías, E. J., Chemale, F., Castro Dorado, A., 2018, Patagonia-Antarctica Early Paleozoic conjugate margins: Cambrian synsedimentary silicic magmatism, $\mathrm{U}-\mathrm{Pb}$ dating of K-bentonites, and related volcanogenic rocks: Gondwana Research 63, 186-225.

Halliday, A.N., Davidson, J.P., Hildreth, W., Holden, P., 1991, Modelling the petrogenesis of high $\mathrm{Rb} / \mathrm{Sr}$ silicic magmas: Chemical Geology 92, 107-114.

Hartmann, L.A., Santos, J.O.S., 2004, Predominance of high Th/U, magmatic zircon in Brazilian Shield sandstones: Geology, 32(1), 73-76.

Henderson, C.M.B., Pierozynski, W.J., 2012, An experimental study of Sr, Ba, and $\mathrm{Rb}$ partitioning between alkali feldspar and silicate liquid in the system nepheline-kalsilite quartz at $0.1 \mathrm{GPa} \mathrm{P}(\mathrm{H} 2 \mathrm{O})$ : a revisitation and assessment: Mineralogical Magazine, 76, 157-190.
Lema, H., Cortés, J.M., 1987, El vulcanismo eoceno del flanco oriental de la meseta de Canquel, Chubut, Argentina, en X Congreso Geológico Argentino: San Miguel de Tucuman, Argentina, Asociación Geológica Argentina, Actas IV,188-191

Le Maitre, R.W, Bateman, P., Dudek, A., Keller, J., Lameyre, J., Le Bas, M.J., Sabine, P.A., Schmid, R., Sorensen, H., Strekeisen; A., Woolley, A.R, Zanettin, B., 1989, A classification of igneous rocks and glossary of terms: Blackwell, Oxford, 193 pp.

Linares E., González, R., 1990, Catálogo de Edades Radimétricas de la República Argentina 1957-1987: Publicaciones Especiales de la Asociación Geológica Argentina, Serie B, 19, 628 pp.

Ludwig, K.R., 2009, Squid 2.5. A user Manual, revised 12 Apr, 2009, Berkeley Geochronology Center: Special Publication 5, 110 pp.

Ludwig, K.R., 2012, Isoplot 3.75. A geochronological toolkit for Microsoft Excel, revised 30th January: Berkeley Geochronology Center Special Publication 5, 75 pp.

Naipauer, M., Sato, A.M., González, P.D., Chemale Jr., F., Varela, R., Llambías, E.J., Grecco, G.A., Dnatas, E., 2010, Eopaleozoic Patagonia-East Antartica connection: fossil and $\mathrm{U}-\mathrm{Pb}$ evidence from $\mathrm{El} \mathrm{Jagüelito} \mathrm{Formation,} \mathrm{en} \mathrm{VII}$ South American Symposium on Isotope Geology: Brasília, Brasil, Instituto de Geociênças, Universidade de Brasilia, Digital Proceedings, 602-605.

Nullo, F. 1978. Descripción Geológica de la Hoja 41d, Lipetrén, provincia de Río Negro: Buenos Aires, Argentina, Servicio Geológico Nacional, Boletín 158, 1-88.

Orgeira, M.J., Remesal, M.B., 1993, Estudio Paleomagnético del Complejo Volcánico Somuncura, Argentina: Revista de la Asociación Geológica Argentina, 48(3-4), 257-264.

Pankhurst, R.J., Rapela, C.W., Fanning, C.M., Márquez, M., 2006, Gondwanide continental collision and the origin of Patagonia: Earth-Science Reviews $76,235-257$.

Rapalini, A.E., López de Luchi, M., Tohver, E., Cawood, P. A., 2013.The South American ancestry of the North Patagonian Massif: geochronological evidence for an autochthonous origin?: Terra Nova, 25 (4), 337-342.

Remesal, M. B., 1988, Geología y petrología de los basaltos de la meseta de Somuncurá: Buenos Aires, Argentina, Departamento Ciencias Geológicas, Facultad de Ciencias Exactas y Naturales, Universidad de Buenos Aires, tesis doctoral, $211 \mathrm{pp}$.

Remesal, M.B., Salani, F.M., 2018, Edad K-Ar del Complejo Volcánico Agua de la Piedra en Puesto Suárez, Río Negro: Revista del Museo de Ciencias Naturales Bernardino Rivadavia, 20(1), 35-43.

Remesal, M.B., Salani, F., Franchi, M., Ardolino, A.A., 2001, Hoja Geológica 4169-IV, Maquinchao. Provincia de Río Negro: . Buenos Aires, Instituto de Geología y Recursos Minerales, Servicio Geológico Minero Argentino, Boletín 312, 1- 72 .

Remesal, M.B., Salani, F.M., Franchi, M.R., Ardolino, A.A., 2002, Complejo Volcánico Agua de la Piedra. Patagonia Extrandina Norte, en XV Congreso Geológico Argentino: Calafate, Argentina, Asociación Geológica Argentina, Actas 1, 161-166.

Remesal, M.B., Salani, F.M., Massaferro, G.I., Cerredo, M.E., 2004, Estratigrafia y petrología del sector noreste de sierra de Apas, provincia del Chubut: Revista de la Asociación Geológica Argentina. Geología de la Patagonia, 59 (4), 578-590.

Remesal, M.B., Salani, F.M., Cerredo, M.E., 2006. Caracterización petrológica del Complejo Volcánico Agua de La Piedra, provincia de Río Negro, en $8^{\circ}$ Congreso de Mineralogía y Metalogenia, Buenos Aires, Acta Avances en Mineralogía, Metalogenia y Petrología, 427-434.

Remesal, M.B., Salani, F.M., Cerredo, M.E., 2012, Petrología del Complejo Volcánico Barril Niyeu (Mioceno inferior), Patagonia Argentina. Petrology of the Barril Niyeu Volcanic Complex (Early Miocene), Patagonia Argentina: Revista Mexicana de Ciencias Geológicas, 29(2), 463-477.

Salani, F.M.,1990, Caracterización geológica y petrológica del vulcanismo áciddo terciario de la sierra de Pire Mahuida, provincia del Chubut: Buenos Aires, Argentina, Departamento Ciencias Geológicas, Facultad de Ciencias Exactas y Naturales, Universidad de Buenos Aires, tesis doctoral, 161 pp.

Salani, F.M., 1996 , Los domos riolíticos del Macizo de Ñancuyique, Patagonia Extraandina Argentina, en XII Congreso Geológico Boliviano: Tarija, Bolivia, Sociedad Geológica Boliviana, Actas II, 445-453.

Salani, F.M., Remesal, M.B., Franchi, M., Ardolino, A.A., 2001. La asociación gabro sienita de la Formación Cerro Cortado en los cerros Pilquiniyeu, sur 
de Río Negro, Argentina, en XI Congreso Latinoamericano de Geología y III Congreso Uruguayo de Geología: Montevideo, Uruguay, Sociedad Uruguaya de Geologia, en soporte magnético, Contribución núm. 199, $6 \mathrm{pp}$.

Salani, F.M., Remesal, M.B., Cerredo, M.E., 2006, Las rocas traquíticas del Complejo Volcánico Barril Niyeu, en $8^{\circ}$ Congreso de Mineralogía y Metalogenia: Buenos Aires, Argentina, Asociación Mineralógica Argentina, Acta Avances en Mineralogía, Metalogenia y Petrología, 413-420.

Salani, F.M., Remesal, M.B., Cerredo, M.E., Franchi, M., Ardolino, A.A., 2006. Contribution to the age of the Somún Curá Post-Plateau Events. Extra Andean Argentinean Patagonia, en Gaucher, C., Bossi, J. (eds.), V South American Symposium on Isotope Geology (SSAGI): Punta del Este, Uruguay, Universidad de la República, 415-419.

Salani F. M, Remesal, M., Cerredo, M. E., 2010, The neogene Barril Niyeu Volcanic Complex. Somún Curá magmatic province. Northern extra andean Patagonia. Argentina: Bollettino di Geofisica teórica ed applicata, $51,85-88$.

Salani, F.M., Santos, J.O.S., 2014, U-Th-Pb SHRIMP ages for the Miocene Pire Mahuida Volcanic Complex, Somún Curá Magmatic Province, Patagonia, Argentina, en 9th South American Symposium on Isotope Geology: Sao Paulo, Brazil, Instituto de Geociencias, Universidad de San Pablo, Abstracts, 165.

Salani, F.M., Santos, J.O.S., Pertille, J., 2014, Cronología de los Eventos Volcánicos Cenozoicos en la Sierra Pire Mahuida, Patagonia Argentina, en XIX Congreso Geológico Argentino, Simposio Vulcanismo de los Andes: Córdoba, Argentina, Asociación Geológica Argentina, Actas, S24, 1-7.

Simpson, G.G., 1941, The Eogene of Patagonia: New York, American Museum Novitates, 1120, 1-15.
Somoza, R., Ghidella, M.E., 2005, Convergencia en el margen occidental de América del Sur durante el Cenozoico: subducción de las placas de Nazca, Farallón y Aluk: Revista de la Asociación Geológica Argentina, 60(4), 797-809.

Stern, R.A., 2001, A new isotopic and trace element standard for the ion microprobe: preliminary thermal ionization mass spectrometry (TIMS) $\mathrm{U}-\mathrm{Pb}$ and electron microprobe data: Geological Survey of Canada, Catalogue M44-2001/F1E-IN, 1-16.

Sun, S.S., McDonough, W.F., 1989, Chemical and isotopic systematics of oceanic basalts: implications for mantle composition and processes, en Saunders, A.D. and M.J. Norry (eds.), Magmatism in the Ocean Basins: Geological Society Special Publication No. 42, 313-345.

Vavra, G., Schmid, R., Gebauer, D., 1999, Internal morphology, habit and $\mathrm{U}-\mathrm{Th}-\mathrm{Pb}$ microanalysis of amphibolite-to-granulite facies zircons: Geochronology of the Ivrea Zone (Southern Alps): Contributions to Mineralogy and Petrology, 134, 380-404.

Vietto, M.E., Bitschene, P. R., 1994, Geology, petrology and style of emplacement of alcaline basalts at the southern border of the Golfo San Jorge basin (central Patagonia, Argentina): Zentralblatt für Geologie und Paläontologie, Teil I H (7/8), 739-752.

Volkheimer, 1973, Observaciones geológicas en el área de Ingeniero Jacobacci y adyacencias (provincia de Río Negro): Revista Asociación Geológica Argentina, 28(1), 13-36.

Manuscrito recibido: junio 26, 2018

Manuscrito corregido recibido: noviembre 28, 2018

Manuscrito aceptado: enero 8, 2019 